\title{
Objects that direct visuospatial attention produce the search advantage for facing dyads
}

Article

Accepted Version

Vestner, T., Over, H., Gray, K. L. H. and Cook, R. (2021)

Objects that direct visuospatial attention produce the search advantage for facing dyads. Journal of Experimental

Psychology: General. ISSN 1939-2222 doi:

https://doi.org/10.1037/xge0001067 Available at https://centaur.reading.ac.uk/96598/

It is advisable to refer to the publisher's version if you intend to cite from the work. See Guidance on citing.

To link to this article DOI: http://dx.doi.org/10.1037/xge0001067

Publisher: American Psychological Association

All outputs in CentAUR are protected by Intellectual Property Rights law, including copyright law. Copyright and IPR is retained by the creators or other copyright holders. Terms and conditions for use of this material are defined in the End User Agreement.

www.reading.ac.uk/centaur 
Central Archive at the University of Reading

Reading's research outputs online 
In press at: Journal of Experimental Psychology: General

\title{
Objects that direct visuospatial attention produce the search advantage for facing dyads
}

Tim Vestner ${ }^{1}$, Harriet Over ${ }^{2}$, Katie L. H. Gray ${ }^{3}$, and Richard Cook ${ }^{1,2^{*}}$

\author{
${ }^{1}$ Department of Psychological Sciences, \\ Birkbeck, University of London, London, U.K. \\ ${ }^{2}$ Department of Psychology, \\ University of York, York, U.K. \\ ${ }^{3}$ School of Psychology and Clinical Language Sciences, \\ University of Reading, Reading, U.K.
}

${ }^{*}$ Corresponding author:

richard.cook@bbk.ac.uk

Department of Psychological Sciences,

Birkbeck, University of London,

Malet Street,

London, U.K., WC1E7HX 


\begin{abstract}
When hidden amongst pairs of individuals facing in the same direction, pairs of individuals arranged front-to-front are found faster in visual search tasks than pairs of individuals arranged back-to-back. Two rival explanations have been advanced to explain this search advantage for facing dyads. According to one account, the search advantage reflects the fact that front-to-front targets engage domain-specific social interaction processing that helps stimuli compete more effectively for limited attentional resources. Another view is that the effect is a by-product of the ability of individual heads and bodies to direct observers' visuospatial attention. Here, we describe a two-part investigation that sought to test these accounts. First, we found that it is possible to replicate the search advantage with non-social objects. Next, we employed a cueing paradigm to investigate whether it is the ability of individual items to direct observers' visuospatial attention that determines if an object category produces the search advantage for facing dyads. We found that the strength of the cueing effect produced by an object category correlated closely with the strength of the search advantage produced by that object category. Taken together, these results provide strong support for the directional cueing account.
\end{abstract}

\title{
Key words:
}

Social perception; Social interactions; Search advantage for facing dyads; Visual search; Attentional cueing; Domain-general processing 


\section{Introduction}

Traditionally, social perception research has focussed on the visual processing of individual faces (Duchaine \& Yovel, 2015; Freiwald, Duchaine, \& Yovel, 2016), bodies (Peelen \& Downing, 2007; Ramsey, 2018), and actions (Blake \& Shiffrar, 2007; Cook, Bird, Catmur, Press, \& Heyes, 2014). In recent years, however, there has been growing interest in how human observers perceive, attend to, and recall social interactions viewed from third-person perspectives (Gray, Barber, Murphy, \& Cook, 2017; Isik, Koldewyn, Beeler, \& Kanwisher, 2017; Papeo, Stein, \& Soto-Faraco, 2017; Quadflieg, Gentile, \& Rossion, 2015). One of the interesting findings to emerge from this new literature is the search advantage for facing dyads. When hidden amongst pairs of individuals facing in the same direction, pairs of individuals arranged front-to-front are found faster in visual search tasks than pairs of individuals arranged back-to-back (Vestner, Gray, \& Cook, 2020, 2021; Vestner, Tipper, Hartley, Over, \& Rueschemeyer, 2019). Similarly, facing targets hidden amongst back-to-back distractors are found faster than back-to-back targets hidden amongst facing distractors (Papeo, Goupil, \& Soto-Faraco, 2019; Vestner et al., 2021).

According to one account, this search advantage reflects the fact that front-to-front targets are processed as social interactions, and therefore engage domain-specific social interaction processing that helps stimuli compete more effectively for limited attentional and perceptual resources. Conversely, back-to-back arrangements are not thought to be processed as social interactions, and thus do not benefit from domain-specific processing (Papeo, 2020; Papeo et al., 2019). This domain-specific account accords with related suggestions that i) front-to-front arrangements engage distinct regions of visual cortex, not recruited by back-to-back arrangements (Abassi \& Papeo, 2020), and ii) that an innate preference for front-to-front over back-to-back arrangements helps to canalise the emergence of perceptual expertise for social interactions (Beier \& Spelke, 2012; Papeo, Nicolas, \& Hochmann, 2020).

A rival view is that the search advantage for facing dyads is a by-product of the differential configuration of direction cues present in front-to-front and back-to-back arrangements (Vestner et al., 2020). Human faces and bodies are salient directional cues that exert a strong influence on how observers distribute their attention (Frischen, Bayliss, \& Tipper, 2007; Langton, Watt, \& Bruce, 2000; Nummenmaa \& Calder, 2009). Front-to-front arrangements may create a 'hot-spot' - a relatively small region of space to which attention is directed by multiple cues. These hot-spots may guide observers' attention to the target location relatively early in a serial visual search (Vestner et al., 2020, 2021). Conversely, the individual elements in back-to-back arrangements direct observers' attention away from the target location. As a result, observers may find the target location later in a serial visual search. 
The directional cueing account is a domain-general explanation and predicts that the search advantage for facing dyads should also be produced by "non-social" objects, provided they direct observers' visuospatial attention. Consistent with this view, a similar search advantage has been described for pairs of arrows. Target pairs arranged 'point-to-point' are found faster than target pairs arranged 'base-to-base' (Vestner et al., 2020). Insofar as arrows are nonsocial, this result suggests that the search advantage for facing dyads is a product of domaingeneral attentional mechanisms, rather than the social nature of the dyads.

However, the status of arrows as "non-social" has been contested (Furlanetto, Becchio, Samson, \& Apperly, 2016). It is well established that, under certain conditions, adults and children anthropomorphise geometric shapes (Abell, Happe, \& Frith, 2000; Heider \& Simmel, 1944; Over \& Carpenter, 2009). Importantly, arrows may have stronger social connotations than most geometric shapes because they are a symbolic instruction from one human mind to another to attend in a particular direction. As a result, children learn to understand them as ostensive or communicative cues (Wu, Tummeltshammer, Gliga, \& Kirkham, 2014). Consistent with this view, Pellicano and Rhodes (2003) have shown that 3- to 4-year-old children are able to infer an actor's desire for a particular food item from observing an arrow cue. Indeed, children inferred the mental state of an actor more reliably from an arrow than from a gaze cue. It is therefore conceivable that pairs of arrows arranged point-to-point may be processed as a social interaction.

Here we describe a two-part investigation that advances our understanding of the search advantage for facing dyads. In the first part, we examine whether it is possible to replicate the search advantage with common 3D objects that we can touch and manipulate. The observation of the search advantage with everyday objects would further support the view that this effect is the product of domain-general mechanisms. In the second part, we employ a cueing paradigm to investigate whether the ability of individual items to direct observers' visuospatial attention determines whether a stimulus class produces the search advantage for facing dyads. Consistent with the predictions of the directional cueing hypothesis, we were able to replicate the search advantage with several common everyday objects. Importantly, i) only those objects that cued visuospatial attention produced the search advantage for facing dyads, and ii) the strength of the cueing effect produced by an object category correlated closely with the strength of the associated search advantage.

\section{Online testing and participant recruitment}

All the experiments described were conducted online, an approach that is increasingly common. Carefully-designed online tests of cognitive and perceptual processing can yield 
high-quality data, indistinguishable from that collected in the lab (Crump, McDonnell, \& Gureckis, 2013; Germine et al., 2012; Woods, Velasco, Levitan, Wan, \& Spence, 2015). The experiments were coded using Unity3D (Version 2018.3.7f1), compiled to WebGL, and hosted on an Amazon Lightsail server. Response times (RTs) were recorded locally on participants' computers without being influenced by variations in data transmission speed to the server. We have previously confirmed that this method produces similar RT distributions to those seen in the lab (Vestner et al., 2020).

Participants were recruited through Prolific (www.prolific.co). All were native English speakers with a prolific approval rate of at least $75 \%$. Each experiment was completed by separate groups of participants (i.e., each sample was completely independent). The sample size for each experiment was determined a priori using a power analysis, assuming a moderate effect size $\left(d_{z}=0.5\right)$ and a target power of 0.8 . Our assumption of a moderate effect size was based on our previous studies of this effect (Vestner et al., 2020, 2021; Vestner et al., 2019). This analysis yielded a target sample size of 34 , which was rounded up to 40 . Ethical clearance was granted by the local ethics committee and the experiment was conducted in line with the ethical guidelines laid down in the 6th (2008) Declaration of Helsinki. All participants gave informed consent.

\section{Which stimulus classes produce the search advantage for facing dyads?}

When hidden amongst pairs of individuals facing in the same direction, pairs of individuals arranged front-to-front are found faster in visual search tasks, than pairs of individuals arranged back-to-back (Vestner et al., 2020, 2021; Vestner et al., 2019). In our first set of experiments, we examined whether we could replicate this search advantage for facing dyads with human bodies and nine common everyday objects that have a canonical 'front' and 'back' (cameras, cars, chairs, desk fans, guns, desk lamps, bicycles, power drills, and shoes).

\section{Methods}

The ten experiments described employed the same visual search procedure (Figure 1a) and differed only in terms of the stimuli used to construct the target and distractor pairings (Figure $1 \mathrm{~b}-1 \mathrm{k})$. So that we had a common point of comparison across the different experiments, all participants also completed a variant of the search task with arrow stimuli. For the sake of brevity, the results from the arrows conditions are described in the supplementary materials. We observed the search advantage for facing dyads in the arrows condition of all ten experiments (all p's $<.005$ ). In six of these experiments (human bodies, cameras, cars, desk 
fans, bicycles, power drills), participants' search advantage with arrows correlated significantly with the search advantage produced by the target object.

Figure-1

\section{Stimuli}

Each stimulus category comprised eight different exemplars. We created mirror images of each exemplar so that it could be presented facing left or right. Images were standardized to a height of 350 pixels (human bodies, cameras, chairs, desk fans, desk lamps, and power drills) or 180 pixels (cars, guns, bicycles, and shoes). The images of bodies were sourced from the Adobe Stock Service. The images of cameras, desk lamps, cars, desk fans, guns, chairs, bicycles, power drills, and shoes were sourced online from various websites.

\section{Procedure}

Experimental trials began with an empty screen divided into four quadrants. Participants initiated the trial in their own time by holding down spacebar, causing four stimulus pairings to appear, one in each quadrant. Target pairs could appear front-to-front or back-to-back. The three distractor pairings consisted of the same elements as the target pair but both elements pointed in the same direction (leftwards or rightwards). The three distractors always included at least one rightward and one leftward facing pairing. Participants were instructed to release spacebar as soon as they had found the target. Releasing spacebar caused all four pairs to disappear, preventing participants from continuing their search. The stimulus pairings were then replaced by a keyboard key in each section. Participants indicated the target location by pressing the corresponding key. RTs were measured from stimulus onset until the moment the participant released spacebar. On catch trials, distractor pairs appeared in all four quadrants. In the absence of a target, participants were instructed to keep holding down spacebar until the trial timed-out (after $5 \mathrm{~s}$ ). At the end of each trial, participants were given feedback (correct or incorrect).

In each experiment, participants completed two blocks (front-to-front, back-to-back) in a counterbalanced order. Each block consisted of 50 trials (45 experimental trials, 5 catch trials). Participants were told the target for the visual search at the beginning of each block.

\section{Results}

The results from these experiments are depicted in Figure 2. The search advantage for facing dyads is inferred from faster RTs when target pairings are arranged front-to-front, than backto-back. 
Figure-2

\section{Human Bodies}

Forty participants (13 female, 27 male) with an age-range of 18 to 54 years $\left(M_{\text {age }}=28.2, S D_{\text {age }}\right.$ $=8.8$ ) were recruited through Prolific. No-one was replaced or excluded. All participants completed at least 8 of the 10 catch trials correctly. Those trials where participants responded incorrectly $(1.9 \%)$, or where they took longer than $5 \mathrm{~s}$ to respond (1.3\%), were excluded from the analysis. A search advantage for facing dyads was seen for human bodies. Front-to-front targets $(M=1.77 \mathrm{~s}, S D=0.55 \mathrm{~s})$ were found significantly faster than back-to-back targets $(M$ $=1.97 \mathrm{~s}, S D=0.62 \mathrm{~s})\left[t(39)=5.08, p<.001, d_{z}=0.81, \mathrm{Cl}_{95 \%}=0.11 \mathrm{~s}, 0.27 \mathrm{~s}\right]$.

\section{Cameras}

Forty participants (17 female, 22 male, 1 non-binary) with an age-range of 18 to 52 years $\left(M_{\text {age }}=31.5, S D_{\text {age }}=9.7\right)$ were recruited through Prolific. No-one was replaced or excluded. All participants completed at least 7 of the 10 catch trials correctly. Those trials where participants responded incorrectly (1.5\%), or where they took longer than $5 \mathrm{~s}$ to respond $(1.0 \%)$, were excluded from the analysis. A search advantage for facing dyads was seen for cameras. Front-to-front targets $(M=2.26 \mathrm{~s}, S D=0.50 \mathrm{~s})$ were found significantly faster than back-to-back targets $(M=2.46 \mathrm{~s}, S D=0.56 \mathrm{~s})\left[t(39)=5.08, p<.001, d_{z}=0.80, \mathrm{Cl}_{95 \%}=0.12\right.$ $\mathrm{s}, 0.29 \mathrm{~s}]$.

\section{Cars}

Forty participants (21 female, 19 male) with an age-range of 18 to 54 years $\left(M_{\text {age }}=31.1, S D_{\text {age }}\right.$ $=10)$ were recruited through Prolific. No-one was replaced or excluded. All participants completed at least 7 of the 10 catch trials correctly. Those trials where participants responded incorrectly $(2.2 \%)$, or where they took longer than $5 \mathrm{~s}$ to respond $(1.1 \%)$, were excluded from the analysis. A search advantage for facing dyads was seen for cars. Front-to-front targets $(M$ $=1.69 \mathrm{~s}, S D=0.38 \mathrm{~s})$ were found significantly faster than back-to-back targets $(M=1.81 \mathrm{~s}$, $S D=0.34 \mathrm{~s})\left[t(39)=4.37, p<.001, d_{z}=0.69, \mathrm{Cl}_{95 \%}=0.06 \mathrm{~s}, 0.18 \mathrm{~s}\right]$.

\section{Chairs}

Forty participants (20 female, 19 male, 1 non-binary) with an age-range of 18 to 54 years $\left(M_{\text {age }}=30.5, S D_{\text {age }}=9.4\right)$ were recruited through Prolific. No-one was replaced or excluded. All participants completed at least 7 of the 10 catch trials correctly. Those trials where participants responded incorrectly (1.8\%), or where they took longer than $5 \mathrm{~s}$ to respond (1.2\%), were excluded from the analysis. A search advantage for facing dyads was not seen for chairs. RTs for front-to-front targets $(M=1.97 \mathrm{~s}, S D=0.54 \mathrm{~s})$ and back-to-back targets $(M$ 
$=2.03 \mathrm{~s}, S D=0.49 \mathrm{~s})$ did not differ significantly $\left[t(39)=1.09, p=.281, d_{z}=0.17, \mathrm{Cl}_{95 \%}=-0.05\right.$ $\mathrm{s}, 0.18 \mathrm{~s}]$.

Desk fans

Forty participants (24 female, 16 male) with an age-range of 18 to 51 years $\left(M_{\text {age }}=33.4, S D_{\text {age }}\right.$ $=9.3$ ) were recruited through Prolific. No-one was replaced or excluded. All participants completed at least 8 of the 10 catch trials correctly. Those trials where participants responded incorrectly $(2.1 \%)$, or where they took longer than $5 \mathrm{~s}$ to respond $(1.1 \%)$, were excluded from the analysis. A search advantage for facing dyads was seen for desk fans. Front-to-front targets $(M=1.70 \mathrm{~s}, S D=0.43 \mathrm{~s})$ were found significantly faster than back-to-back targets $(M$ $=1.86 \mathrm{~s}, S D=0.49 \mathrm{~s})\left[t(39)=5.56, p<.001, d_{z}=0.88, \mathrm{Cl}_{95 \%}=0.10 \mathrm{~s}, 0.21 \mathrm{~s}\right]$.

\section{Guns}

Forty participants (20 female, 18 male, 2 non-binary) with an age-range of 18 to 56 years $\left(M_{\text {age }}=32.0, S D_{\text {age }}=10.0\right)$ were recruited through Prolific. No-one was replaced or excluded. All participants completed at least 8 of the 10 catch trials correctly. Those trials where participants responded incorrectly $(1.8 \%)$, or where they took longer than $5 \mathrm{~s}$ to respond $(0.9 \%)$, were excluded from the analysis. A search advantage for facing dyads was not seen for guns. RTs for front-to-front targets $(M=1.52 \mathrm{~s}, S D=0.30 \mathrm{~s})$ and back-to-back targets $(M=$ $1.56 \mathrm{~s}, S D=0.35 \mathrm{~s})$ did not differ significantly $\left[t(39)=1.63, p=.111, d_{z}=0.26, \mathrm{Cl}_{95 \%}=-0.01\right.$ $\mathrm{s}, 0.05 \mathrm{~s}]$.

\section{Desk lamps}

Forty participants (23 female, 16 male, 1 non-binary) with an age-range of 18 to 57 years $\left(M_{\text {age }}=31.5, S D_{\text {age }}=10.4\right)$ were recruited through Prolific. No-one was replaced or excluded. All participants completed at least 7 of the 10 catch trials correctly. Those trials where participants responded incorrectly $(1.6 \%)$, or where they took longer than $5 \mathrm{~s}$ to respond $(1.2 \%)$, were excluded from the analysis. A search advantage for facing dyads was seen for desk lamps. Front-to-front targets $(M=1.81 \mathrm{~s}, S D=0.52 \mathrm{~s})$ were found significantly faster than back-to-back targets $(M=2.04 \mathrm{~s}, S D=0.49 \mathrm{~s})\left[t(39)=6.40, p<.001, d_{z}=1.01, \mathrm{Cl}_{95 \%}=\right.$ $0.16 \mathrm{~s}, 0.30 \mathrm{~s}]$.

\section{Bicycles}

Forty participants (18 female, 22 male) with an age-range of 19 to 60 years $\left(M_{\text {age }}=32.9, S D_{\text {age }}\right.$ $=11.7)$ were recruited through Prolific. No-one was replaced or excluded. All participants completed at least 6 of the 10 catch trials correctly. Those trials where participants responded incorrectly $(1.7 \%)$, or where they took longer than $5 \mathrm{~s}$ to respond $(0.6 \%)$, were excluded from the analysis. A search advantage for facing dyads was seen for bicycles. Font-to-front targets 
$(M=1.38 \mathrm{~s}, S D=0.21 \mathrm{~s})$ were found significantly faster than back-to-back targets $(M=1.47$ $\mathrm{s}, S D=0.20 \mathrm{~s})\left[t(39)=2.30, p=.027, d_{z}=0.36, \mathrm{Cl}_{95 \%}=0.01 \mathrm{~s}, 0.17 \mathrm{~s}\right]$.

\section{Power drills}

Forty participants (20 female, 20 male) with an age-range of 18 to 60 years $\left(M_{\text {age }}=33.3, S D_{\text {age }}\right.$ $=12.7$ ) were recruited through Prolific. No-one was replaced or excluded. All participants completed at least 7 of the 10 catch trials correctly. Those trials where participants responded incorrectly $(1.8 \%)$, or where they took longer than $5 \mathrm{~s}$ to respond $(1.0 \%)$, were excluded from the analysis. A search advantage for facing dyads was seen for power drills. Font-to-front targets $(M=1.41 \mathrm{~s}, S D=0.31 \mathrm{~s})$ were found significantly faster than back-to-back targets $(M$ $=1.65 \mathrm{~s}, S D=0.36 \mathrm{~s})\left[t(39)=5.50, p<.001, d_{\mathrm{z}}=0.87, \mathrm{Cl}_{95 \%}=0.15 \mathrm{~s}, 0.32 \mathrm{~s}\right]$.

\section{Shoes}

Forty participants (18 female, 22 male) with an age-range of 18 to 56 years $\left(M_{\text {age }}=32.9, S D_{\text {age }}\right.$ $=12.5$ ) were recruited through Prolific. No-one was replaced or excluded. All participants completed at least 6 of the 10 catch trials correctly. Those trials where participants responded incorrectly $(2.1 \%)$, or where they took longer than $5 \mathrm{~s}$ to respond $(1.2 \%)$, were excluded from the analysis. A search advantage for facing dyads was not seen for shoes. RTs for front-tofront targets $(M=1.77 \mathrm{~s}, S D=0.52 \mathrm{~s})$ and back-to-back targets $(M=1.80 \mathrm{~s}, S D=0.47 \mathrm{~s})$ did not differ significantly $\left[t(39)=0.55, p=.583, d_{z}=0.09, \mathrm{Cl}_{95 \%}=-0.07 \mathrm{~s}, 0.13 \mathrm{~s}\right]$.

\section{Directional cueing of visuospatial attention by single items}

In our first series of experiments, we observed the search advantage for facing dyads with human bodies, cameras, cars, desk fans, desk lamps, bicycles, and power drills. However, chairs, guns, and shoes failed to produce the search advantage despite the fact that they have a canonical 'front' and 'back'. According to the directional cueing hypothesis, certain objects - like upright faces (Frischen et al., 2007; Nummenmaa \& Calder, 2009), bodies (Vestner et al., 2021), and arrows (Kuhn \& Kingstone, 2009; Tipples, 2002) - produce the search advantage because they direct visuospatial attention in a fast and automatic (i.e., hardto-inhibit) manner. Objects that do not direct visuospatial attention in this way would not be expected to produce the effect. In our second series of experiments, we sought to determine whether the ability of a stimulus class to produce the search advantage for facing dyads, is determined by the ability of single exemplars to direct observers' visuospatial attention.

\section{Methods}

The ten experiments described below employed the same attentional cueing procedure (Figure 3a) and differed only in terms of the type of cueing stimulus presented (Figure 3b-3k). 
Figure-3

\section{Stimuli}

Each experiment used cueing stimuli drawn from a particular category: human bodies, cameras, cars, chairs, desk fans, guns, desk lamps, bicycles, power drills, or shoes. The pool of stimulus images was the same as those employed in the visual search experiments described earlier. Images were standardized to a height of 400 pixels (human bodies, cameras, chairs, desk fans, desk lamps, and power drills) or 200 pixels (cars, guns, bicycles, and shoes).

\section{Procedure}

Experimental trials began with a fixation cross in the centre of the screen. After $2 \mathrm{~s}$, a cueing stimulus appeared in the centre, replacing the fixation cross. On $50 \%$ of trials this stimulus faced rightwards, on $50 \%$ of trials this stimulus faced leftwards. After a further $500 \mathrm{~ms}$, two letter arrays appeared on screen, one on the left and one on the right, each consisting of 6 letters arranged vertically. Target letters were chosen randomly from a pool of 13 letters [E, F, $H, K, L, M, N, T, V, W, X, Y, Z]$ chosen for their linear components and angular features. The remaining letters were used to populate the arrays. In total, the procedure consisted of eight blocks of 24 trials. Each block comprised 8 valid trials (the central stimulus cued the array containing the target letter), 8 invalid trials (the central stimulus cued the array that did not contain the target letter), and 8 catch trials (the target letter was not present).

At the start of each block, participants were given a target letter to find on each trial of that block. Participants were asked to press spacebar as quickly as possible if the target letter was present in one of the arrays. Where the target letter was not present (catch trials), participants were instructed to simply wait until the trial timed-out (after $4 \mathrm{~s}$ ). At the end of each trial, participants were given feedback in the form of the word 'correct' (following a spacebar response during target-present trials or no response during target-absent trials), the word 'incorrect' (following a spacebar response during target-absent trial), or the phrase 'too slow' (following a failure to respond within $4 \mathrm{~s}$ on target-present trials). Where participants responded incorrectly or too slowly, they were then reminded of the target letter.

\section{Results}

The results from this series of experiments are depicted in Figure 4. For each type of stimulus, a directional cueing effect is inferred from faster RTs on valid trials than on invalid trials.

Figure-4 


\section{Human bodies}

Forty participants (21 female, 18 male, 1 non-binary) with an age-range of 18 to 57 years $\left(M_{\text {age }}=30.1, S D_{\text {age }}=9.7\right)$ were recruited through Prolific. No-one was replaced or excluded. Those trials where participants responded incorrectly (1.9\%) were excluded from the analysis. All participants performed correctly on at least 61 of the 64 catch trials. A cueing effect was seen for human bodies. Participants responded significantly faster on valid trials $(M=1.18 \mathrm{~s}$, $S D=1.23 \mathrm{~s})$ than on invalid trials $(M=1.23 \mathrm{~s}, S D=0.21 \mathrm{~s})\left[t(39)=3.16, p=.003, d_{z}=0.50\right.$, $\left.\mathrm{Cl}_{95 \%}=0.02 \mathrm{~s}, 0.08 \mathrm{~s}\right]$.

\section{Cameras}

Forty participants (14 female, 25 male, 1 non-binary) with an age-range of 18 to 56 years $\left(M_{\text {age }}=28.1, S D_{\text {age }}=8.6\right)$ were recruited through Prolific. No-one was replaced or excluded.

Those trials where participants responded incorrectly $(1.7 \%)$ were excluded from the analysis. All participants performed correctly on at least 61 of the 64 catch trials. A cueing effect was seen for cameras. Participants responded significantly faster on valid trials $(M=1.17 \mathrm{~s}, S D=$ $0.25 \mathrm{~s})$ than on invalid trials $(M=1.21 \mathrm{~s}, S D=0.26 \mathrm{~s})\left[t(39)=2.49, p=.017, d_{z}=0.39, \mathrm{Cl}_{95 \%}=\right.$ $0.01 \mathrm{~s}, 0.07 \mathrm{~s}]$.

\section{Cars}

Forty participants (15 female, 24 male, 1 non-binary) with an age-range of 18 to 53 years $\left(M_{\text {age }}=29.5, S D_{\text {age }}=10.1\right)$ were recruited through Prolific. No-one was replaced or excluded. Those trials where participants responded incorrectly (1.8\%) were excluded from the analysis. All participants performed correctly on at least 62 of the 64 catch trials. A cueing effect was seen for cars. Participants responded significantly faster on valid trials $(M=1.20 \mathrm{~s}, S D=0.24$

$\mathrm{s})$ than on invalid trials $(M=1.25 \mathrm{~s}, S D=0.24 \mathrm{~s})\left[t(39)=2.19, p=.034, d_{z}=0.35, \mathrm{Cl}_{95 \%}=0.01\right.$ $\mathrm{s}, 0.10 \mathrm{~s}]$.

\section{Chairs}

Forty participants ( 15 female, 25 male) with an age-range of 18 to 60 years ( $M_{\text {age }}=32.7, S D_{\text {age }}$ $=11.1$ ) were recruited through Prolific. No-one was replaced or excluded. Those trials where participants responded incorrectly $(2.0 \%)$ were excluded from the analysis. All participants performed correctly on at least 61 of the 64 catch trials. We did not observe a cueing effect for chairs. There was no significant difference between RTs on valid trials $(M=1.26 \mathrm{~s}, S D=0.24$ $\mathrm{s})$ and on invalid trials $(M=1.28 \mathrm{~s}, S D=0.24 \mathrm{~s})\left[t(39)=1.01, p=.318, d_{z}=0.16, \mathrm{Cl}_{95}=-0.02\right.$ s, $0.07 \mathrm{~s}]$. 


\section{Desk fans}

Forty participants (21 female, 17 male, 2 non-binary) with an age-range of 18 to 53 years $\left(M_{\text {age }}=27.6, S D_{\text {age }}=9.0\right)$ were recruited through Prolific. No-one was replaced or excluded. Those trials where participants responded incorrectly (1.9\%) were excluded from the analysis. All participants performed correctly on at least 59 of the 64 catch trials. A cueing effect was seen for desk fans. Participants responded significantly faster on valid trials $(M=1.13 \mathrm{~s}, S D=$ $0.22 \mathrm{~s})$ than on invalid trials $(M=1.20 \mathrm{~s}, S D=0.23 \mathrm{~s})\left[t(39)=3.72, p=.001, d_{z}=0.59, \mathrm{Cl}_{95 \%}=\right.$ $0.03 \mathrm{~s}, 0.10 \mathrm{~s}]$.

\section{Guns}

Forty participants (16 female, 23 male, 1 non-binary) with an age-range of 18 to 56 years $\left(M_{\text {age }}=31.8, S D_{\text {age }}=10.3\right)$ were recruited through Prolific. No-one was replaced or excluded. Those trials where participants responded incorrectly $(1.7 \%)$ were excluded from the analysis. All participants performed correctly on at least 62 of the 64 catch trials. We did not observe a cueing effect for guns. There was no significant difference between RTs on valid trials $(M=$ $1.23 \mathrm{~s}, S D=0.24 \mathrm{~s})$ and on invalid trials $(M=1.26 \mathrm{~s}, S D=0.22 \mathrm{~s})\left[t(39)=1.58, p=.123, d_{z}=\right.$ $\left.0.25, \mathrm{Cl}_{95}=-0.01 \mathrm{~s}, 0.07 \mathrm{~s}\right]$.

\section{Desk lamps}

Forty participants (14 female, 25 male, 1 non-binary) with an age-range of 18 to 48 years $\left(M_{\text {age }}=29.6, S D_{\text {age }}=8.2\right)$ were recruited through Prolific. No-one was replaced or excluded. Those trials where participants responded incorrectly (2.0\%) were excluded from the analysis. All participants performed correctly on at least 60 of the 64 catch trials. A cueing effect was seen for desk lamps. Participants responded significantly faster on valid trials $(M=1.22 \mathrm{~s}, S D$ $=0.27 \mathrm{~s})$ than on invalid trials $(M=1.28 \mathrm{~s}, S D=0.23 \mathrm{~s})\left[t(39)=2.41, p=.021, d_{z}=0.38, \mathrm{Cl}_{95 \%}\right.$ $=0.01 \mathrm{~s}, 0.10 \mathrm{~s}$.

\section{Bicycles}

Forty participants (19 female, 20 male, 1 non-binary) with an age-range 19 to 57 years $\left(M_{\text {age }}=\right.$ 30.6, $\left.S D_{\text {age }}=10.5\right)$ were recruited through Prolific. No-one was replaced or excluded. Those trials where participants responded incorrectly (1.5\%) were excluded from the analysis. All participants performed correctly on at least 61 of the 64 catch trials. A cueing effect was seen for desk fans. Participants responded significantly faster on valid trials $(M=1.15 \mathrm{~s}, S D=0.18$ s) than on invalid trials $(M=1.19 \mathrm{~s}, S D=0.20 \mathrm{~s})\left[t(39)=2.34, p=.024, d_{z}=0.37, \mathrm{Cl}_{95 \%}=0.01\right.$ $\mathrm{s}, 0.08 \mathrm{~s}]$. 


\section{Power drills}

Forty participants (17 female, 22 male, 1 non-binary) with an age-range of 18 to 47 years $\left(M_{\text {age }}=30.7, S D_{\text {age }}=7.4\right)$ were recruited through Prolific. No-one was replaced or excluded. Those trials where participants responded incorrectly (1.6\%) were excluded from the analysis. All participants performed correctly on at least 61 of the 64 catch trials. A cueing effect was seen for power drills. Participants responded significantly faster on valid trials $(M=1.15 \mathrm{~s}, S D$ $=0.21 \mathrm{~s})$ than on invalid trials $(M=1.20 \mathrm{~s}, S D=0.20 \mathrm{~s})\left[t(39)=2.38, p=.022, d_{z}=0.38, \mathrm{Cl}_{95 \%}\right.$ $=0.01 \mathrm{~s}, 0.08 \mathrm{~s}]$.

\section{Shoes}

Forty participants (14 female, 24 male, 2 non-binary) with an age-range of 18 to 58 years $\left(M_{\text {age }}=33.6, S D_{\text {age }}=11.1\right)$ were recruited through Prolific. No-one was replaced or excluded. Those trials where participants responded incorrectly (1.7\%) were excluded from the analysis. All participants performed correctly on at least 61 of the 64 catch trials. We did not observe a cueing effect for shoes. There was no significant difference between RTs on valid trials $(M=$ $1.20 \mathrm{~s}, S D=0.25 \mathrm{~s})$ and on invalid trials $(M=1.22 \mathrm{~s}, S D=0.24 \mathrm{~s})\left[t(39)=0.83, p=.413, d_{z}=\right.$ $\left.0.13, \mathrm{Cl}_{95}=-0.02 \mathrm{~s}, 0.05 \mathrm{~s}\right]$.

\section{Comparing the relative strength of the two effects}

In our first series of experiments, we replicated the search advantage for facing dyads with human bodies, cameras, cars, desk fans, desk lamps, bicycles, and power drills. Chairs, guns, and shoes failed to produce the search advantage. In our second set of experiments, we observed significant direction cueing effects for human bodies, cameras, cars, desk fans, desk lamps, bicycles and power drills. Chairs, guns, and shoes failed to produce significant cueing effects. In other words, only those stimulus categories that produced significant direction cueing effects, produced significant search advantage effects. The similar patterns of significance / non-significance seen in these experiments accord well with the direction cueing account of the search advantage for facing dyads.

Next, we sought direct statistical evidence for the relationship between the direction cueing and visual search effects. To this end we subjected the effect sizes observed $\left(d_{z}\right)$ in the visual search and direction cueing experiments to correlational analyses (Figure 5). We found that the strength of the cueing effect produced by the ten stimulus categories correlated closely with the strength of the associated search advantage $\left[r_{p}=.818, p=.004\right]$. This correlation was also significant when we restricted the analysis to the nine non-social object categories (i.e., excluding human bodies) $\left[r_{p}=.811, p=.009\right]$. Thus, there is no sense in which the correlation is being driven by the presence of a social category. 
Figure-5

\section{General discussion}

The search advantage for facing dyads

When hidden amongst pairs of individuals facing in the same direction, pairs of individuals arranged front-to-front are found faster in visual search tasks than pairs of individuals arranged back-to-back (Vestner et al., 2020, 2021; Vestner et al., 2019). Similarly, front-tofront targets hidden amongst back-to-back distractors are found faster than back-to-back targets hidden amongst front-to-front distractors (Papeo et al., 2019; Vestner et al., 2020). Two rival explanations have been advanced to explain this search advantage for facing dyads. According to one account, the search advantage reflects the fact that front-to-front targets engage domain-specific social interaction processing that helps stimuli compete more effectively for limited attentional and perceptual resources (Papeo, 2020; Papeo et al., 2019). A rival view is that the search advantage for facing dyads is a by-product of the ability of individual heads and bodies to direct observers' visuospatial attention (Vestner et al., 2020, 2021). The experiments described here sought to test these rival accounts.

In our first experiment, we asked whether it is it possible to replicate the search advantage for facing dyads with common 3D objects that also possess a canonical front and back. We employed nine object categories: cameras, cars, chairs, desk fans, guns, desk lamps, bicycles, power drills, and shoes. We were able to replicate the search advantage for facing dyads with six of these categories - cameras, cars, desk fans, desk lamps, bicycles, and power drills. The fact that we were able to replicate the search advantage with several common objects challenges the view that the effect is the product of domain-specific social interaction processing (Papeo, 2020; Papeo et al., 2019). Had human bodies produced a stronger search advantage than non-social stimuli, it may have been possible to salvage a domain-specific account. However, the search advantage seen with bodies was no greater (i.e., the effect size was smaller) than that seen with desk fans, desk lamps, and power drills. Instead, these findings support a domain-general explanation.

In Study 2, we sought to understand the nature of the process that produces the search advantage for facing dyads. Interestingly, in Study 1, whereas some non-social objects produced the search advantage (cameras, cars, desk fans, desk lamps, bicycles, and power drills), others did not (chairs, guns, and shoes). We reasoned that these discrepant results may be because only some of these object types direct observers' attention. Using a cueing procedure, we thus examined the ability of the nine types of object to direct observers' visuospatial attention. Tellingly, only those object classes that produced the search advantage 
for facing dyads produced significant cueing effects (cameras, cars, desk fans, desk lamps, bicycles, and power drills). Chairs, guns, and shoes did not produce the search advantage for facing dyads and failed to yield significant cueing effects. The strength of the visual search effect - the search advantage for facing dyads - produced by a given stimulus category correlated closely with the strength of the attentional cueing effect produced by that category.

These findings support the view that the search advantage for facing dyads is a by-product of the ability of individual heads and bodies to direct observers' visuospatial attention (Vestner et al., 2020, 2021). When arranged front-to-front, strong directional cues may create a small focal region to which observers' attention is guided. The presence of these hot-spots may aid a serial visual search for front-to-front targets regardless of whether the stimuli are social or not. Conversely, when arranged back-to-back, the same cues direct observers' attention away from the target location, hindering visual search (Vestner et al., 2020). If this account is correct, eye-tracking may reveal interesting differences in fixation behaviour when participants engage in visual search for front-to-front and back-to-back targets.

We cannot rule out the possibility that social stimuli (faces and bodies) and non-social stimuli (arrows, objects) produce the search advantage for facing dyads via different neurocognitive mechanisms. To date, however, there is no evidence that the search advantage produced by faces and bodies is qualitatively different from the effects produced by arrows and objects. Instead, a domain-general attentional cueing account provides a single parsimonious explanation of the extant data. The results described here suggest that it is the ability of individual items to cue attention that determines which types of non-social object produce the search advantage for facing dyads. Given that faces and bodies are known to be such effective directional cues, it would be surprising if they did not produce the search advantage for facing dyads via the same mechanism.

\section{The cueing of visuospatial attention by objects}

Much has been written about the ability of social attention cues (Frischen et al., 2007; Langton et al., 2000; Nummenmaa \& Calder, 2009) and arrows (Kuhn \& Kingstone, 2009; Tipples, 2002) to direct observers' visuospatial attention. To date, however, the ability of common objects to direct visuospatial attention has been largely over-looked. One exception is a study described by Roberts and Humphreys (2011) in which action-related objects were found to cue visuospatial attention in the direction implied by their intended use. For example, screwdrivers cued attention towards the expected location of a screw. The directionality implied by their intended use may well explain the strong cueing effects produced by power drills in our second set of experiments. Interestingly, however, several of the other cueing effects seen in our study appear to be unrelated to action-affordances. Instead, desk lamps, 
desk fans, and cameras may direct observers' attention because their orientation frequently predicts the presence and location of items-of-interest in our visual environment. Similarly, vehicles, such as cars and bicycles, may direct attention in their conventional direction of travel. This kind of attentional orienting may help observers anticipate how a dynamic scene is likely to unfold.

It is also noteworthy that several objects with a front-back axis failed to cue participants' visuospatial attention (chairs, shoes, and guns). Although chairs and shoes both have a canonical front and back, they also afford downwards actions; people sit down on a vacant chair, or put their foot into a shoe. The presence of these affordances may prevent items from cueing attention leftwards or rightwards. The failure of guns to cue attention is curious, not least because of their superficial resemblance to power drills. It is possible that this has something to do with weapon focus (e.g., Loftus \& Messo, 1987; Steblay, 1992); for example, the ability of guns to cue attention may be hampered by their saliency. Alternatively, participants may find that their attention is simultaneously drawn towards the location of the person holding a weapon, as well as towards the location of potential victims, thereby preventing systematic cueing effects. It is important that future research establish whether these findings apply to all chairs, shoes, and guns, or whether some exemplars do cue visuospatial attention.

Our findings show that several common objects direct observers' visuospatial attention in an automatic (i.e., hard-to-inhibit) manner. Importantly, the nature and strength of the directional cueing produced by these objects appears to be sufficient to produce the search advantage for facing dyads. As we allude to above, however, it is likely that different types of objects cue participants attention for different reasons. Similarly, we note that objects do not necessarily cue attention in the same way as arrows and / or faces. It is possible that the directional cueing effects produced by social attention cues, arrows, and objects, have different temporal characteristics; for example, the cueing effects seen for objects may manifest a little later (Roberts \& Humphreys, 2011). Similarly, evidence from neuropsychological patients suggests that the cueing effects produced by arrows and gaze-cues may dissociate (Akiyama et al., 2006). Observers may also be better able to inhibit direction cueing by arrows than by gaze (Friesen, Ristic, \& Kingstone, 2004).

\section{The perception of social interactions}

The exciting literature on the visual perception of social interactions is still in its infancy, and paradigms are still being refined. Several studies have sought to compare the effects of frontto-front vs. back-to-back presentation on the visual processing of people and non-social objects (Papeo et al., 2017; Vestner et al., 2019). In these studies, the choice of non-social 
object - chairs (Papeo et al., 2017) and wardrobes (Vestner et al., 2019) - is often a little arbitrary. Our findings suggest a more principled approach. Importantly, we show that not all objects with a front-back axis cue attention. Objects such as desk fans are more closely matched with human faces and bodies because they not only have a canonical front and back, but they also cue observers' visuospatial attention. Thus, where an arrangement manipulation modulates the processing of people but not desk fans, authors can make a stronger case that the effect is a marker of social interaction processing, and not a by-product of attentional cueing.

The reported findings also have implications for neuroimaging work seeking to uncover the neural bases of social interaction perception. The front-to-front vs. back-to-back manipulation has been used in several neuroimaging studies (Abassi \& Papeo, 2020; Isik et al., 2017; Quadflieg et al., 2015) that have sought to compare the visuo-cognitive processing of interacting and non-interacting people. When interpreting the findings from these studies, it is important to remember that the front-to-front vs. back-to-back manipulation not only disrupts the percept of social interaction, but also changes how participants distribute their attention across the stimulus display. Under this paradigm, it may be hard to distinguish neural markers of social interaction processing from the well-documented effects of attentional modulation (Chawla, Rees, \& Friston, 1999; Reynolds \& Chelazzi, 2004; Treue \& Maunsell, 1996).

\section{Domain-specificity and domain-generality}

During peer-review, it has been put to us that the fact that we failed to observe a search advantage for three of the objects tested (chairs, guns, and shoes) argues against a domaingeneral interpretation of the effect. Rather, it has been suggested that our findings are equally consistent with a domain-specific account. This objection is based on the view that a domaingeneral explanation predicts a search advantage for any object with a recognizable front and back. In light of this concern, we wish to clarify what should and should not be expected from the (domain-general) direction cueing account.

In this context, a useful point of comparison is the domain-general account of configural face processing proposed by Isabel Gauthier and colleagues (Gauthier \& Tarr, 1997; Richler, Wong, \& Gauthier, 2011; Wong, Palmeri, \& Gauthier, 2009). According to this view, non-face objects with certain properties, including a canonical 'upright' orientation and a prototypical arrangement of 'first-order' features, can also come to elicit configural processing where participants have extensive experience of individuating exemplars. It is not the case that all non-face objects are thought to engage configural processing; rather, some non-face objects are thought to have the potential to engage configural processing under the right circumstances (e.g., after substantial individuation experience). 
In much the same way, the "domain-general" cueing account does not predict that all objects with a front and back produce the search advantage for facing dyads. Instead, the account argues that a wide range of objects have the potential to elicit the effect, provided they cue observers' visuospatial attention. Evidence that cameras, cars, desk fans, desk lamps, bicycles, and power drills produce the search advantage for facing dyads argues for a domain-general view because these findings demonstrate that there is no "social" constraint on the range of potential stimuli that can elicit the effect. The search advantage for facing dyads seems to be an effect produced by objects that cue attention, not just stimuli that imply social interaction.

Our findings suggest that objects can come to cue attention for a variety of reasons: Vehicles (e.g., cars and bicycles) may cue attention in the implied direction of travel; fans, lamps, and cameras may cue attention because they suggest the location of items of interest within a visual scene; tools (e.g., power drills) may cue attention in the direction of their implied use. Irrespective of how or why they cue attention, these objects also produced the search advantage for facing dyads. Although some objects with a front and a back did not produce the search advantage (e.g., shoes and chairs), we speculate that these items might well produce the effect if observers were first trained to expect items of interest (targets) in the implied direction (e.g., in front of a chair or a shoe).

\section{Conclusion}

In summary, we have shown that it is possible to replicate the search advantage for facing dyads with several non-social objects, including cameras, desk fans, desk lamps, and power drills. Tellingly, i) only those objects that cued visuospatial attention produced the search advantage for facing dyads, and ii) the strength of the cueing effect produced by a stimulus category correlated closely with the strength of the search advantage produced by that category. These findings argue against the view that the search advantage for facing dyads is a hallmark of domain-specific social interaction processing. Instead, these finding favour the view that the search advantage is a by-product of the ability of social and non-social stimuli to direct observers' visuospatial attention. 


\section{Author Note}

The research described in this article was funded by a Starting Grant awarded by the European Research Council to RC (ERC-STG-715824). HO is also supported by an award from the European Research Council (ERC-STG-755719). KG is supported by an award from the Leverhulme Trust (RPG-2019-394). Data is openly available at the following OSF link: https://osf.io/tsbuf/. Parts of this work were presented at the 2020 Virtual Meeting of the Vision Sciences Society and at the Online Meeting of the Experimental Psychology Society held in July 2020. 


\section{References}

Abassi, E., \& Papeo, L. (2020). The representation of two-body shapes in the human visual cortex. Journal of Neuroscience, 40(4), 852-863.

Abell, F., Happe, F., \& Frith, U. (2000). Do triangles play tricks? Attribution of mental states to animated shapes in normal and abnormal development. Cognitive Development, 15(1), $1-16$.

Akiyama, T., Kato, M., Muramatsu, T., Saito, F., Umeda, S., \& Kashima, H. (2006). Gaze but not arrows: a dissociative impairment after right superior temporal gyrus damage. Neuropsychologia, 44(10), 1804-1810.

Beier, J. S., \& Spelke, E. S. (2012). Infants' developing understanding of social gaze. Child Development, 83(2), 486-496.

Blake, R., \& Shiffrar, M. (2007). Perception of human motion. Annual Review of Psychology, $58,47-73$.

Chawla, D., Rees, G., \& Friston, K. J. (1999). The physiological basis of attentional modulation in extrastriate visual areas. Nature Neuroscience, 2(7), 671-676.

Cook, R., Bird, G., Catmur, C., Press, C., \& Heyes, C. (2014). Mirror neurons: from origin to function. Behavioral and Brain Sciences, 37(2), 177-192.

Crump, M. J., McDonnell, J. V., \& Gureckis, T. M. (2013). Evaluating Amazon's Mechanical Turk as a tool for experimental behavioral research. PloS One, 8(3), e57410.

Duchaine, B., \& Yovel, G. (2015). A revised neural framework for face processing. Annual Review of Vision Science, 1, 393-416.

Freiwald, W., Duchaine, B., \& Yovel, G. (2016). Face processing systems: from neurons to real-world social perception. Annual Review of Neuroscience, 39, 325-346.

Friesen, C. K., Ristic, J., \& Kingstone, A. (2004). Attentional effects of counterpredictive gaze and arrow cues. Journal of Experimental Psychology: Human Perception and Performance, 30(2), 319-329.

Frischen, A., Bayliss, A. P., \& Tipper, S. P. (2007). Gaze cueing of attention: visual attention, social cognition, and individual differences. Psychological Bulletin, 133, 694-724.

Furlanetto, T., Becchio, C., Samson, D., \& Apperly, I. (2016). Altercentric interference in level 1 visual perspective taking reflects the ascription of mental states, not submentalizing. Journal of Experimental Psychology: Human Perception and Performance, 42(2), 158163.

Gauthier, I., \& Tarr, M. J. (1997). Becoming a "Greeble" expert: Exploring mechanisms for face recognition. Vision Research, 37(12), 1673-1682.

Germine, L., Nakayama, K., Duchaine, B. C., Chabris, C. F., Chatterjee, G., \& Wilmer, J. B. (2012). Is the Web as good as the lab? Comparable performance from Web and lab in cognitive/perceptual experiments. Psychonomic Bulletin \& Review, 19(5), 847-857.

Gray, K. L. H., Barber, L., Murphy, J., \& Cook, R. (2017). Social interaction contexts bias the perceived expressions of interactants. Emotion, 17(4), 567-571. 
Heider, F., \& Simmel, M. (1944). An experimental study of apparent behavior. The American Journal of Psychology, 57(2), 243-259.

Isik, L., Koldewyn, K., Beeler, D., \& Kanwisher, N. (2017). Perceiving social interactions in the posterior superior temporal sulcus. Proceedings of the National Academy of Sciences, 114(43), E9145-E9152.

Kuhn, G., \& Kingstone, A. (2009). Look away! Eyes and arrows engage oculomotor responses automatically. Attention, Perception, \& Psychophysics, 71(2), 314-327.

Langton, S. R., Watt, R. J., \& Bruce, V. (2000). Do the eyes have it? Cues to the direction of social attention. Trends in Cognitive Sciences, 4(2), 50-59.

Loftus, G. R., \& Messo, J. (1987). Some facts about "weapon focus". Law and Human Behavior, 11(1), 55-62.

Nummenmaa, L., \& Calder, A. J. (2009). Neural mechanisms of social attention. Trends in Cognitive Sciences, 13(3), 135-143.

Over, H., \& Carpenter, M. (2009). Priming third-party ostracism increases affiliative imitation in children. Developmental Science, 12(3), F1-F8.

Papeo, L. (2020). Twos in human vision. Cortex, 132, 473-478.

Papeo, L., Goupil, N., \& Soto-Faraco, S. (2019). Visual search for people among people. Psychological Science, 30(10), 1483-1496.

Papeo, L., Nicolas, G., \& Hochmann, J. R. (2020). Visual perception grounding of social cognition in preverbal infants. OSF Preprints. doi:https://doi.org/10.31219/osf.io/v7y9x

Papeo, L., Stein, T., \& Soto-Faraco, S. (2017). The two-body inversion effect. Psychological Science, 28, 369-379.

Peelen, M. V., \& Downing, P. E. (2007). The neural basis of visual body perception. Nature Reviews Neuroscience, 8, 636-648.

Pellicano, E., \& Rhodes, G. (2003). The role of eye-gaze in understanding other minds. British Journal of Developmental Psychology, 21(1), 33-43.

Quadflieg, S., Gentile, F., \& Rossion, B. (2015). The neural basis of perceiving person interactions. Cortex, 70, 5-20.

Ramsey, R. (2018). Neural integration in body perception. Journal of Cognitive Neuroscience, $30(10), 1442-1451$.

Reynolds, J. H., \& Chelazzi, L. (2004). Attentional modulation of visual processing. Annual Review of Neuroscience, 27, 611-647.

Richler, J. J., Wong, Y. K., \& Gauthier, I. (2011). Perceptual expertise as a shift from strategic interference to automatic holistic processing. Current Directions in Psychological Science, 20(2), 129-134.

Roberts, K. L., \& Humphreys, G. W. (2011). Action-related objects influence the distribution of visuospatial attention. Quarterly Journal of Experimental Psychology, 64(4), 669-688. 
Steblay, N. M. (1992). A meta-analytic review of the weapon focus effect. Law and Human Behavior, 16(4), 413-424.

Tipples, J. (2002). Eye gaze is not unique: automatic orienting in response to uninformative arrows. Psychonomic Bulletin \& Review, 9(2), 314-318.

Treue, S., \& Maunsell, J. H. (1996). Attentional modulation of visual motion processing in cortical areas MT and MST. Nature, 382(6591), 539-541.

Vestner, T., Gray, K. L. H., \& Cook, R. (2020). Why are social interactions found quickly in visual search tasks? Cognition, 200, 104270.

Vestner, T., Gray, K. L. H., \& Cook, R. (2021). Visual search for facing and non-facing people: The effect of actor inversion. Cognition, 208, 104550.

Vestner, T., Tipper, S. P., Hartley, T., Over, H., \& Rueschemeyer, S. A. (2019). Bound together: Social binding leads to faster processing, spatial distortion, and enhanced memory of interacting partners. Journal of Experimental Psychology: General, 148(7), 1251-1268.

Wong, A. C. N., Palmeri, T. J., \& Gauthier, I. (2009). Conditions for facelike expertise with objects: Becoming a Ziggerin expert-but which type? Psychological Science, 20(9), $1108-1117$.

Woods, A. T., Velasco, C., Levitan, C. A., Wan, X., \& Spence, C. (2015). Conducting perception research over the internet: a tutorial review. PeerJ, 3, e1058.

Wu, R., Tummeltshammer, K. S., Gliga, T., \& Kirkham, N. Z. (2014). Ostensive signals support learning from novel attention cues during infancy. Frontiers in Psychology, 5(251). 
Figures

Figure 1

a

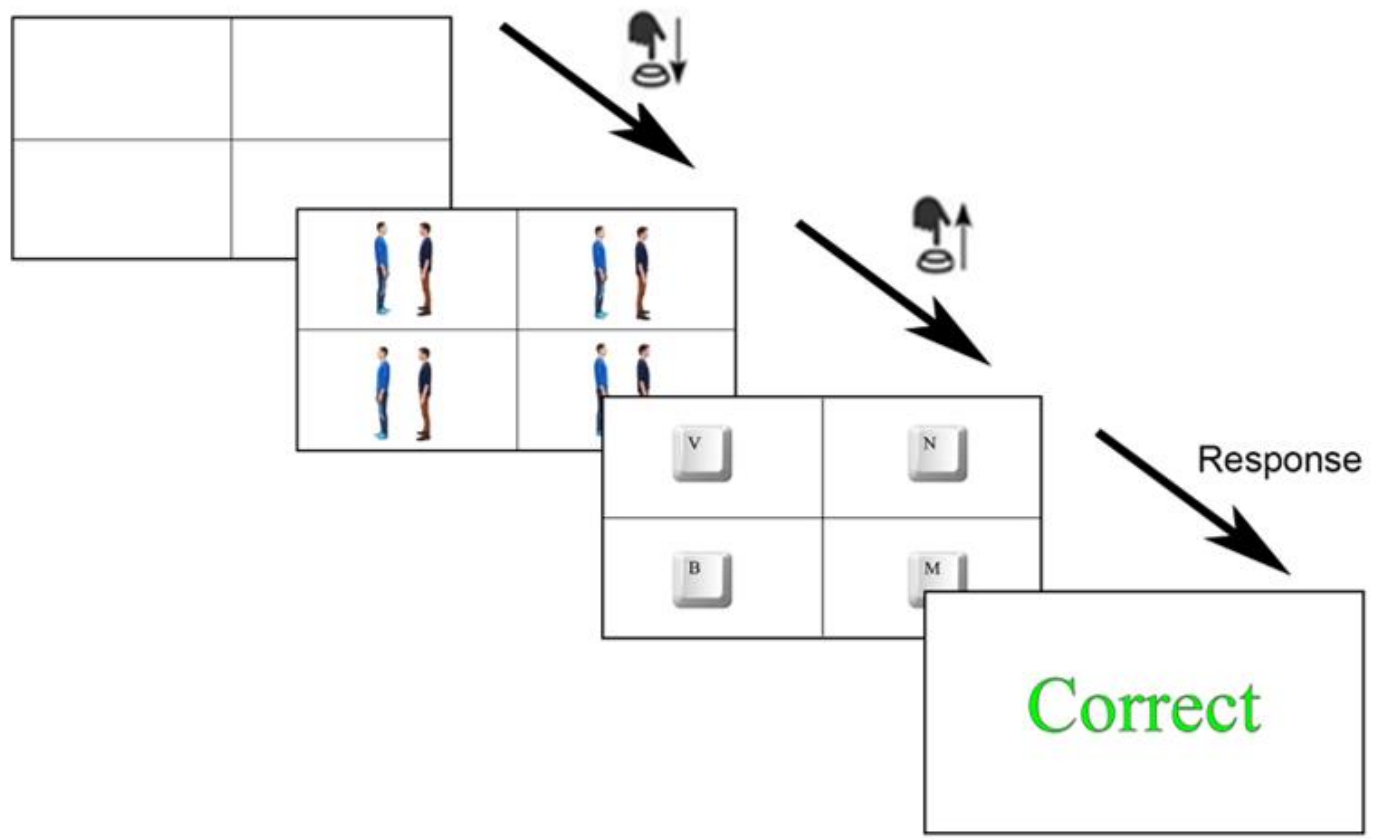

b

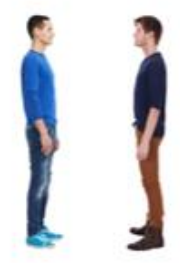

C
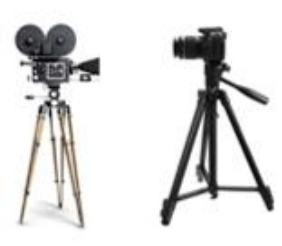

d

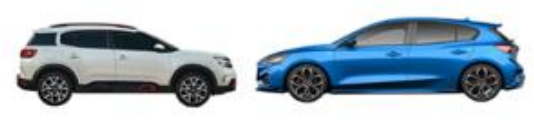

e
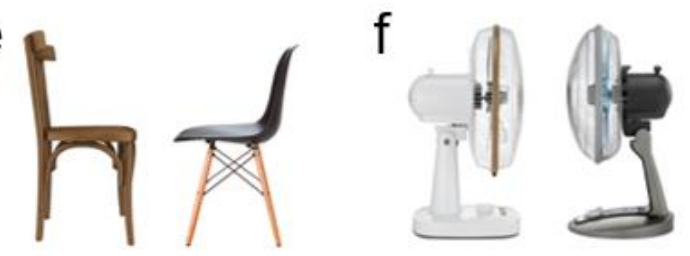

g

$\mathrm{h}$

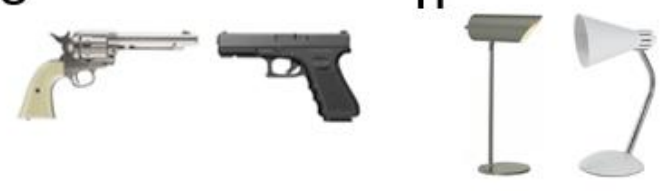

i
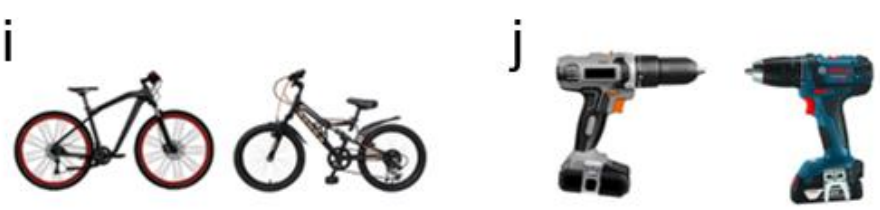

$\mathrm{k}$
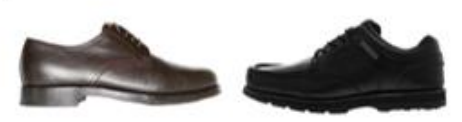

Figure 1. (a) Structure of a trial from the visual search procedure. (b-k) Examples of the stimulus pairs employed in the bodies, cameras, cars, chairs, desk fans, guns, desk lamps, bicycles, power drills, and shoes experiments, respectively. 
Figure 2
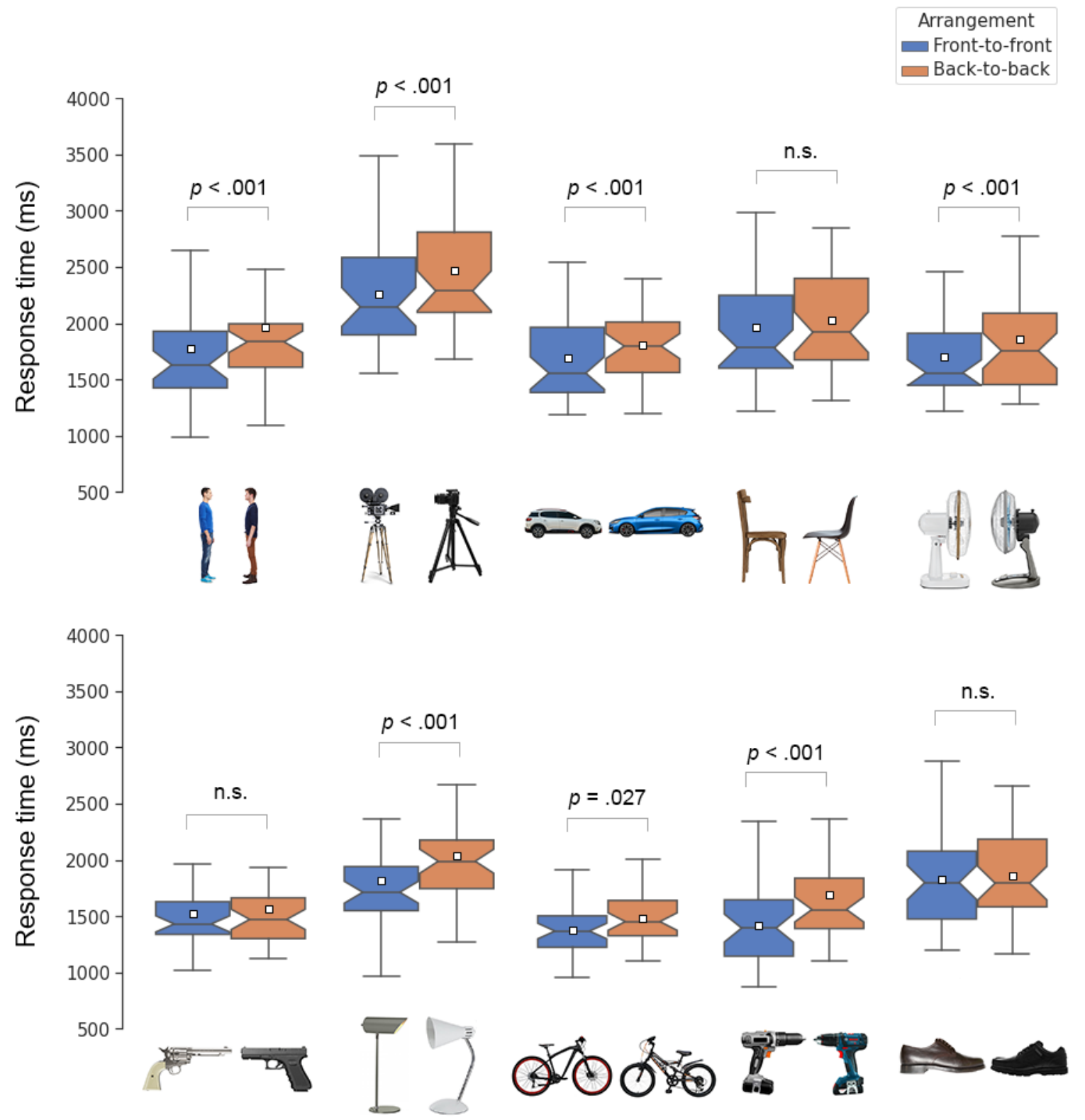

Figure 2. Results from the visual search experiments. Boxes indicate inter-quartile range. Notches indicate confidence interval of the median. Whiskers indicate $1.5{ }^{*}$ interquartile range. White squares denote the mean. 
Figure 3

a

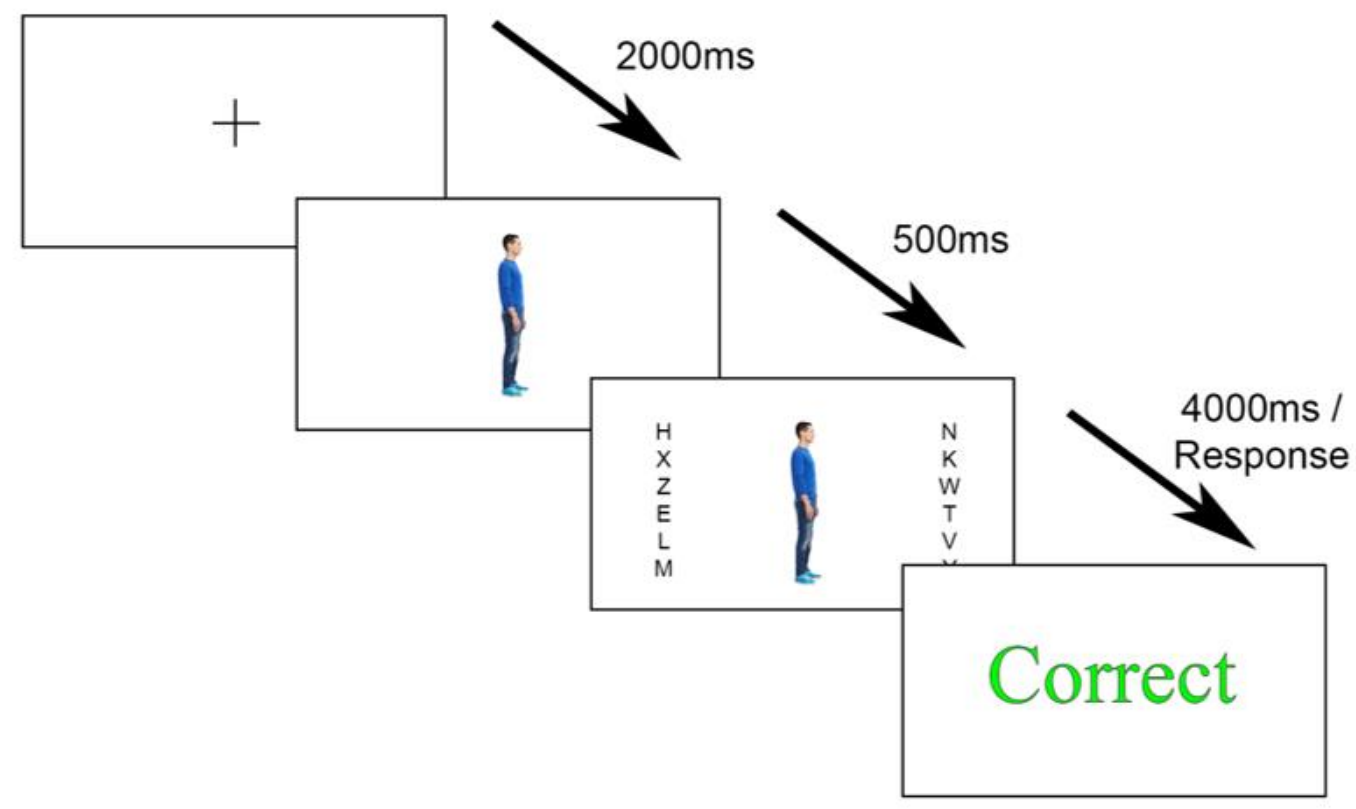

b

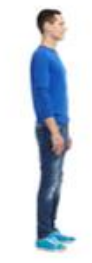

e

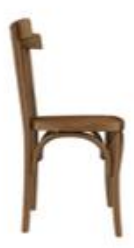

i

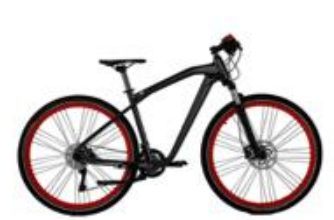

C

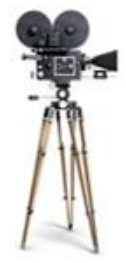

d
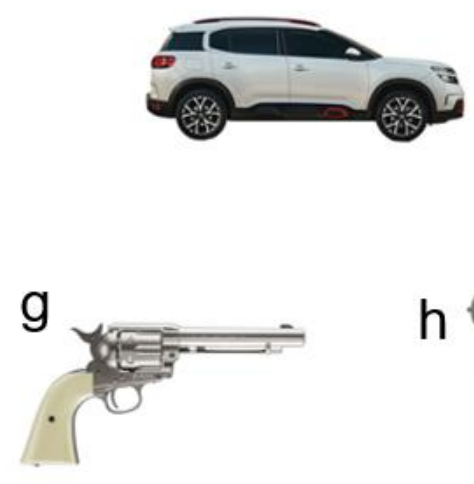

h
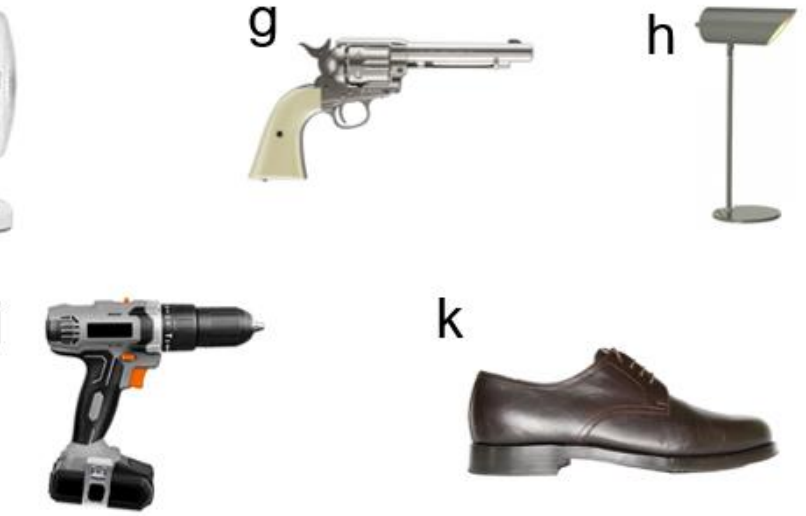

k

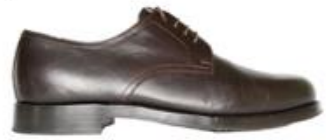

Figure 3. (a) Structure of a trial from the cueing procedure. (b-k) Examples of the cueing stimuli employed in the bodies, cameras, cars, chairs, desk fans, guns, desk lamps, bicycles, power drills, and shoes experiments, respectively. 
Figure 4

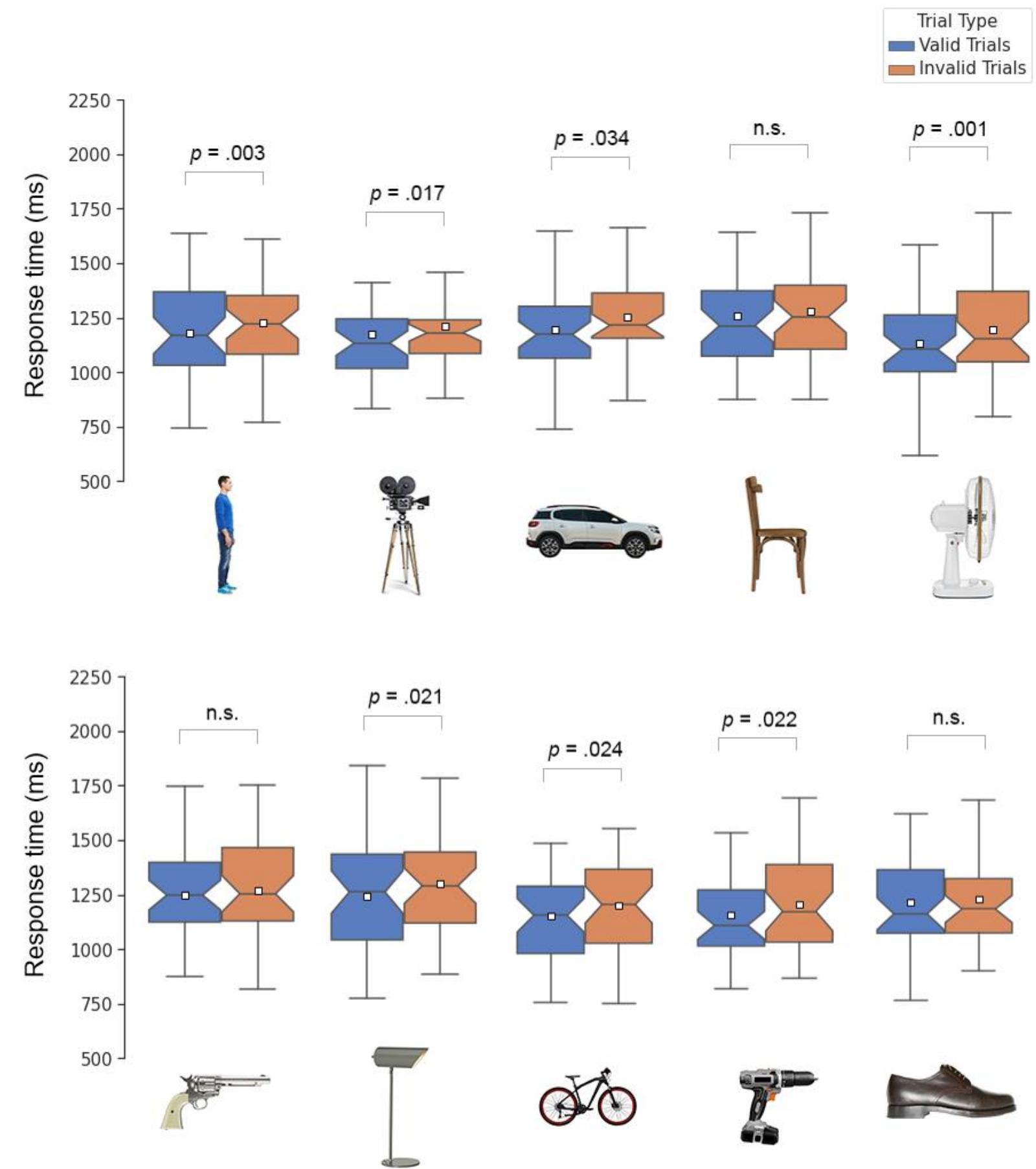

Figure 4. Results from the cueing experiments. Boxes indicate inter-quartile range. Notches indicate confidence interval of the median. Whiskers indicate $1.5^{*}$ interquartile range. White squares denote the mean. 
Figure 5

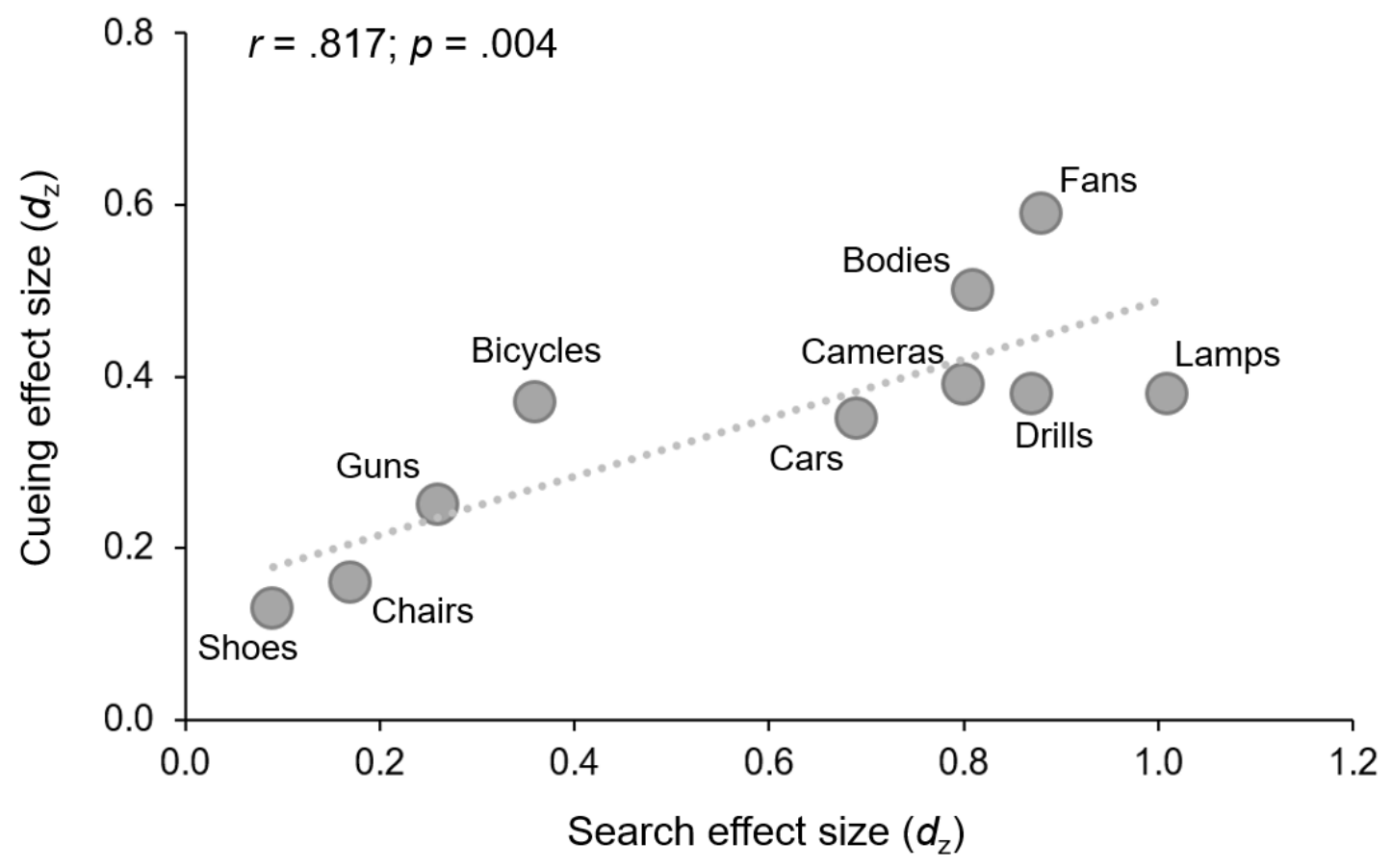

Figure 5. Scatter plot showing the relationship between the strength of the visual search effect (i.e., the search advantage for facing dyads) and the strength of the attentional cueing effect produced by the different types of stimulus. 


\title{
Objects that direct visuospatial attention produce the search advantage for facing dyads
}

\author{
Tim Vestner, Harriet Over, Katie L. H. Gray, and Richard Cook \\ Supplementary material
}

In the main manuscript, we describe ten visual search experiments conducted with human bodies, cameras, cars, chairs, desk fans, guns, desk lamps, bicycles, power drills, and shoes. In each of these experiments, participants also completed the same search task with arrows. The procedure was identical to that described in the main manuscript (example stimuli are shown in Figure S1). In each experiment, half of the participants started with a block of arrows trials (either front-to-front or back-to-back) and half started with a block of object trials (either front-to-front or back-to-back). For the sake of exposition, the results from the ten arrows conditions are presented below as supplementary material. In each experiment, pairs of arrows arranged point-to-point were found faster than pairs arranged base-to-base (all p's < .005), replicating the effect described by Vestner, Gray, \& Cook (2020).
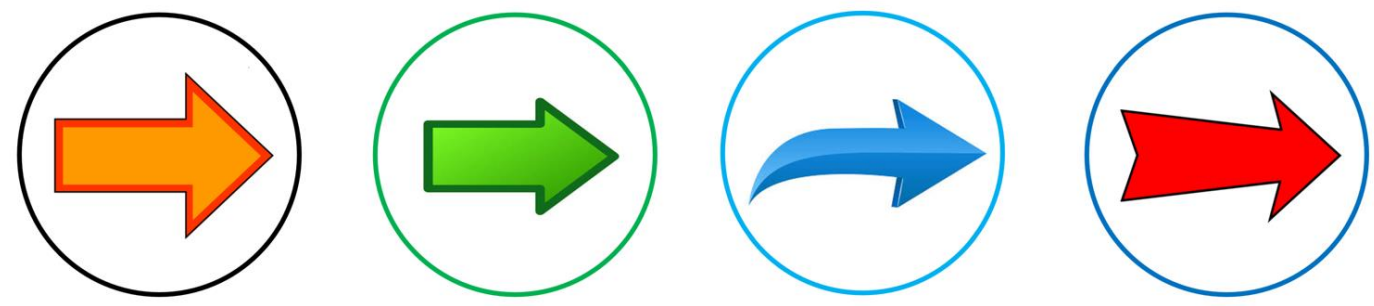

Figure S1. Examples of the arrow stimuli used in the visual search task.

\section{Human bodies}

Results are shown in Figure S2. Those trials where participants responded incorrectly (2\%), or where they took longer than $5 \mathrm{~s}$ to respond $(1.1 \%)$, were excluded from the analysis. The search advantage for facing dyads was seen for arrows. Front-to-front targets $(M=1.76 \mathrm{~s}, S D$ $=0.53 \mathrm{~s})$ were found significantly faster than back-to-back targets $(M=1.94 \mathrm{~s}, S D=0.53 \mathrm{~s})$ $\left[t(39)=6.22, p<.001, d_{z}=0.99, \mathrm{Cl}_{95 \%}=0.12 \mathrm{~s}, 0.24 \mathrm{~s}\right]$. ANOVA with Arrangement (front-tofront, back-to-back) and Stimulus (arrows, human bodies) as within-subjects factors revealed no Arrangement $\times$ Stimulus interaction $\left[F(1,39)=0.11, p=.743, \eta_{p}^{2}=.003\right]$. A significant correlation was seen between participants' search advantage for arrows and bodies $\left[r_{p}=.357\right.$, $p=.024]$.

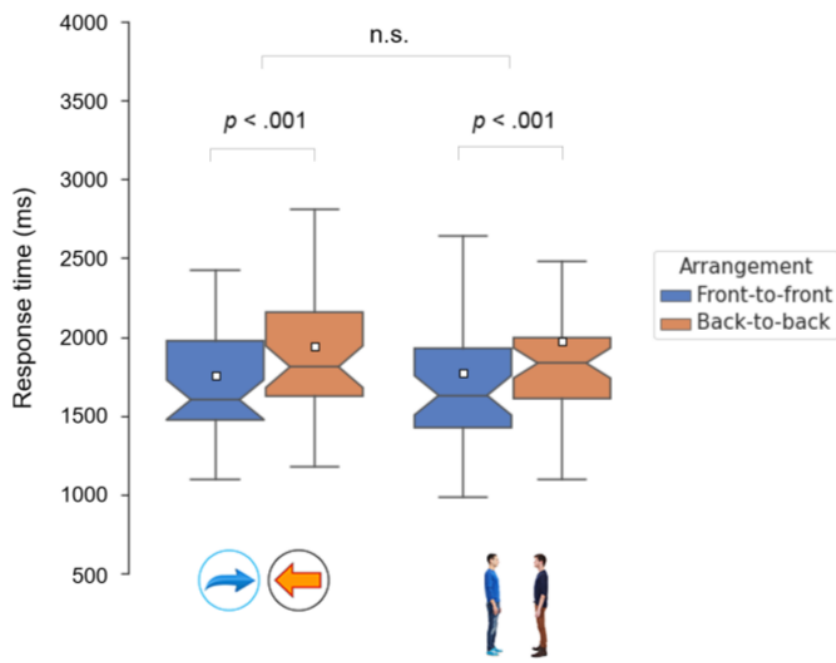

Figure S2. Results from the human bodies experiment. Boxes indicate inter-quartile range. Notches indicate confidence interval of the median. Whiskers indicate $1.5^{*}$ interquartile range. White squares denote the mean. 


\section{Cameras}

Results are shown in Figure S3. Those trials where participants responded incorrectly (1.7\%), or where they took longer than $5 \mathrm{~s}$ to respond $(0.9 \%)$, were excluded from the analysis. The search advantage for facing dyads was seen independently for arrows. Front-to-front targets $(M=1.74 \mathrm{~s}, S D=0.33 \mathrm{~s})$ were found significantly faster than back-to-back targets $(M=1.95$ $\mathrm{s}, S D=0.42 \mathrm{~s})\left[t(39)=5.32, p<.001, d_{z}=0.84, \mathrm{Cl}_{95 \%}=0.13 \mathrm{~s}, 0.29 \mathrm{~s}\right]$. ANOVA with Arrangement (front-to-front, back-to-back) and Stimulus (arrows, cameras) as within-subjects factors revealed no Arrangement $\times$ Stimulus interaction $\left[F(1,39)=0.002, p=.965, \eta_{p}^{2}<\right.$ .001]. A significant correlation was seen between participants' search advantage for arrows and cameras $\left[r_{p}=.451, p=.003\right]$.

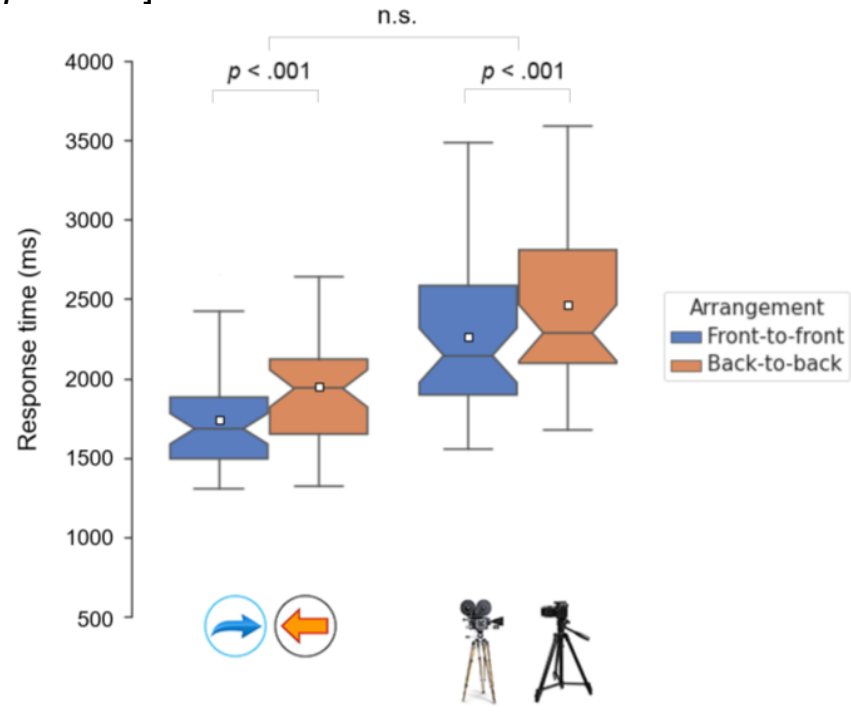

Figure S3. Results from the cameras experiment. Boxes indicate inter-quartile range. Notches indicate confidence interval of the median. Whiskers indicate 1.5 * interquartile range. White squares denote the mean.

Cars

Results are shown in Figure S4. Those trials where participants responded incorrectly (1.9\%), or where they took longer than $5 \mathrm{~s}$ to respond $(1.1 \%)$, were excluded from the analysis. The search advantage for facing dyads was seen independently for arrows. Front-to-front targets $(M=1.69 \mathrm{~s}, S D=0.34 \mathrm{~s})$ were found significantly faster than back-to-back targets $(M=1.88$ $\mathrm{s}, S D=0.44 \mathrm{~s})\left[t(39)=6.52, p<.001, d_{z}=1.03, \mathrm{Cl}_{95 \%}=0.13 \mathrm{~s}, 0.25 \mathrm{~s}\right]$. ANOVA with Arrangement (front-to-front, back-to-back) and Stimulus (arrows, cars) as within-subjects factors revealed no Arrangement $\times$ Stimulus interaction $\left[F(1,39)=3.29, p=.077, \eta_{\mathrm{p}}^{2}=.08\right]$. A significant correlation was seen between participants' search advantage for arrows and cars $\left[r_{p}=.352, p=.026\right]$.

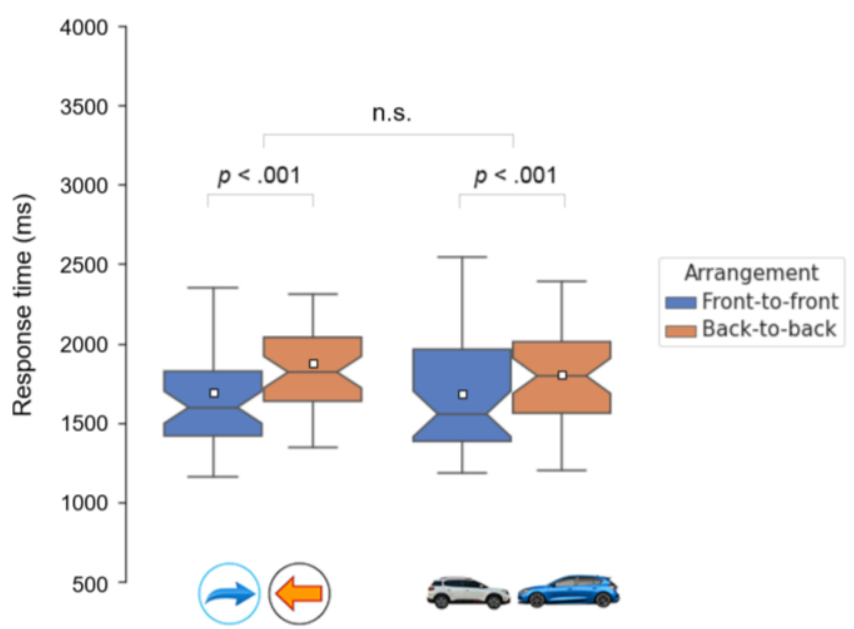

Figure S4. Results from the cars experiment. Boxes indicate inter-quartile range. Notches indicate confidence interval of the median. Whiskers indicate 1.5 * interquartile range. White squares denote the mean. 


\section{Chairs}

Results are shown in Figure S5. Those trials where participants responded incorrectly $(1.7 \%)$, or where they took longer than $5 \mathrm{~s}$ to respond $(1.0 \%)$, were excluded from the analysis. The search advantage for facing dyads was seen independently for arrows. Front-to-front targets $(M=1.73 \mathrm{~s}, S D=0.42 \mathrm{~s})$ were found significantly faster than back-to-back targets $(M=1.96$ $\mathrm{s}, S D=0.54 \mathrm{~s})\left[t(39)=5.71, p<.001, d_{z}=0.90, \mathrm{Cl}_{95 \%}=0.15 \mathrm{~s}, 0.32 \mathrm{~s}\right]$. ANOVA with Arrangement (front-to-front, back-to-back) and Stimulus (arrows, chairs) as within-subjects factors revealed a significant Arrangement $\times$ Stimulus interaction $[F(1,39)=5.55, p=.024$, $\left.\eta \mathrm{p}^{2}=.13\right]$. No correlation was seen between participants' search advantage for arrows and chairs $\left[r_{p}=.006, p=.971\right]$.

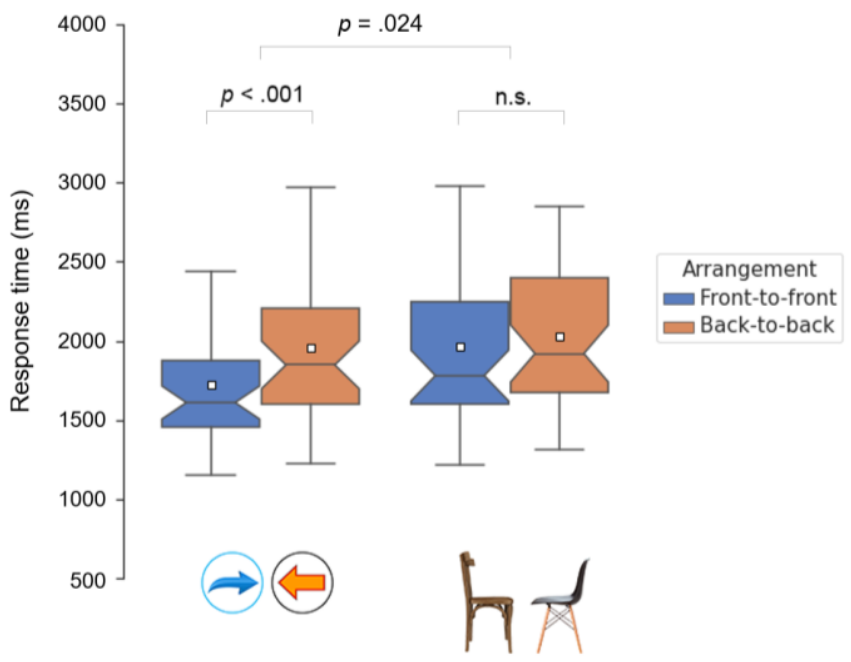

Figure S5. Results from the chairs experiment. Boxes indicate inter-quartile range. Notches indicate confidence interval of the median. Whiskers indicate 1.5 * interquartile range. White squares denote the mean.

\section{Desk fans}

Results are shown in Figure S6. Those trials where participants responded incorrectly (1.8\%), or where they took longer than $5 \mathrm{~s}$ to respond $(1.2 \%)$, were excluded from the analysis. The search advantage for facing dyads was seen independently for arrows. Front-to-front targets $(M=1.73 \mathrm{~s}, S D=0.34 \mathrm{~s})$ were found significantly faster than back-to-back targets $(M=1.93$ $\mathrm{s}, S D=0.41 \mathrm{~s})\left[t(39)=5.79, p<.001, d_{z}=0.92, \mathrm{Cl}_{95 \%}=0.13 \mathrm{~s}, 0.26 \mathrm{~s}\right]$. ANOVA with Arrangement (front-to-front, back-to-back) and Stimulus (arrows, desk fans) as within-subjects factors revealed no Arrangement $\times$ Stimulus interaction $\left[F(1,39)=1.53, p=.223, n p^{2}=.04\right]$. A significant correlation was seen between participants' search advantage for arrows and desk fans $\left[r_{p}=.460, p=.003\right]$.

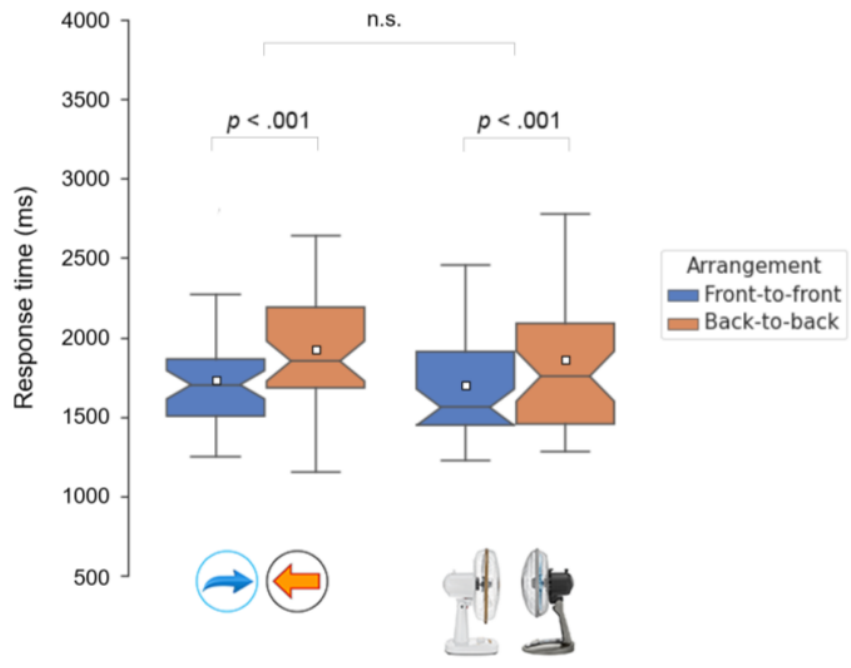

Figure S6. Results from the desk fans experiment. Boxes indicate inter-quartile range. Notches indicate confidence interval of the median. Whiskers indicate $1.5^{*}$ interquartile range. White squares denote the mean. 


\section{Guns}

Results are shown in Figure S7. Those trials where participants responded incorrectly $(1.7 \%)$, or where they took longer than $5 \mathrm{~s}$ to respond $(0.9 \%)$, were excluded from the analysis. The search advantage for facing dyads was seen independently for arrows. Front-to-front targets $(M=1.68 \mathrm{~s}, S D=0.39 \mathrm{~s})$ were found significantly faster than back-to-back targets $(M=1.82$ $\mathrm{s}, S D=0.39 \mathrm{~s})\left[t(39)=5.05, p<.001, d_{z}=0.80, \mathrm{Cl}_{95 \%}=0.08 \mathrm{~s}, 0.19 \mathrm{~s}\right]$. ANOVA with

Arrangement (front-to-front, back-to-back) and Stimulus (arrows, guns) as within-subjects factors revealed a significant Arrangement $\times$ Stimulus interaction $[F(1,39)=8.23, p=.007$, $\left.\eta \mathrm{p}^{2}=.17\right]$. No correlation was seen between participants' search advantage for arrows and guns $\left[r_{p}=.161, p=.321\right]$

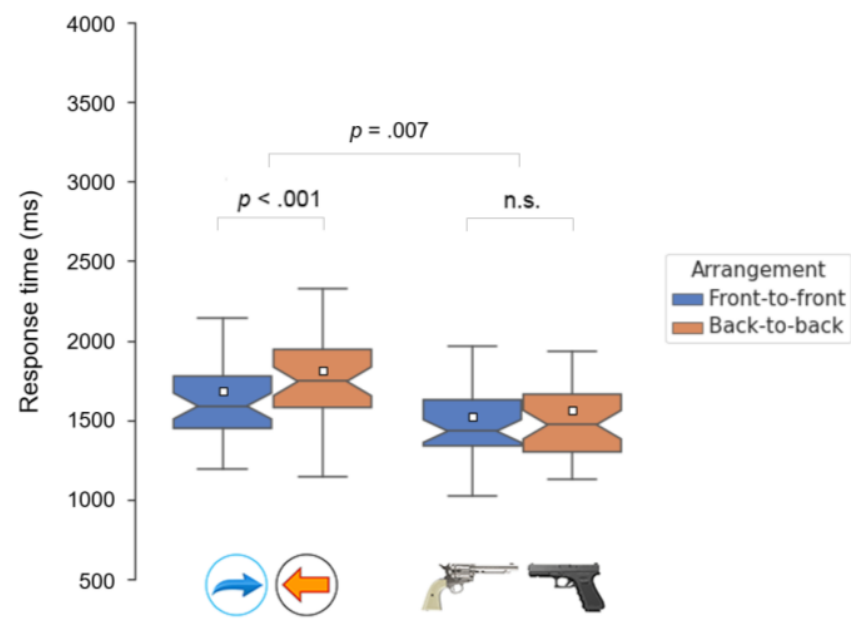

Figure S7. Results from the guns experiment. Boxes indicate inter-quartile range. Notches indicate confidence interval of the median. Whiskers indicate $1.5^{*}$ interquartile range. White squares denote the mean.

\section{Desk lamps}

Results are shown in Figure S8. Those trials where participants responded incorrectly $(1.7 \%)$, or where they took longer than $5 \mathrm{~s}$ to respond $(1.1 \%)$, were excluded from the analysis. The search advantage for facing dyads was seen independently for arrows. Front-to-front targets $(M=1.76 \mathrm{~s}, S D=0.43 \mathrm{~s})$ were found significantly faster than back-to-back targets $(M=1.97$ $\mathrm{s}, S D=0.41 \mathrm{~s})\left[t(39)=5.46, p<.001, d_{z}=0.86, \mathrm{Cl}_{95 \%}=0.13 \mathrm{~s}, 0.28 \mathrm{~s}\right]$. ANOVA with Arrangement (front-to-front, back-to-back) and Stimulus (arrows, desk lamps) as withinsubjects factors revealed no Arrangement $\times$ Stimulus interaction $\left[F(1,39)=0.27, p=.606, n p^{2}\right.$ $=.01]$. No correlation was seen between participants' search advantage for arrows and desk lamps $\left[r_{p}=.190, p=.240\right]$.

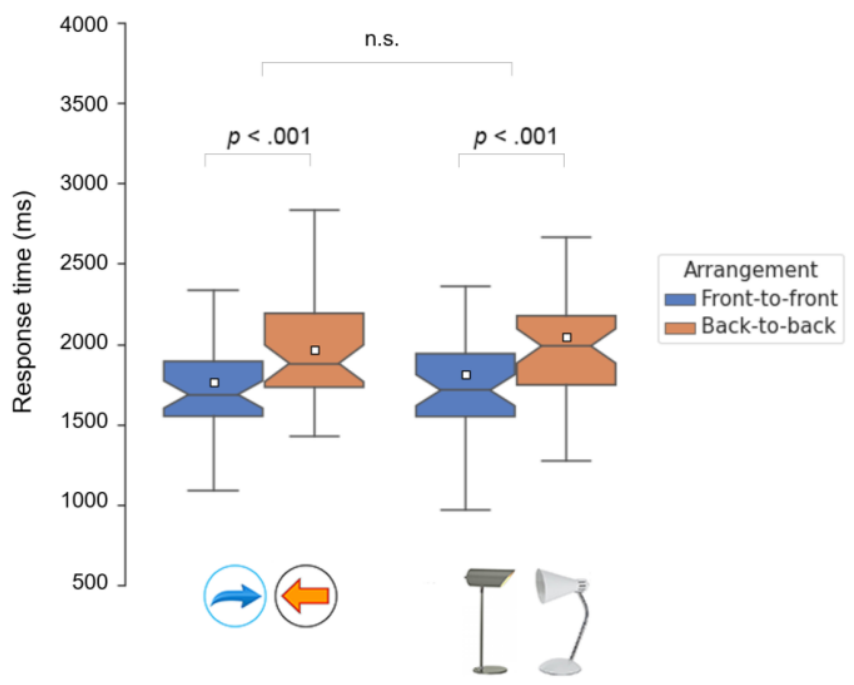

Figure S8. Results from the desk lamps experiment. Boxes indicate inter-quartile range. Notches indicate confidence interval of the median. Whiskers indicate 1.5 * interquartile range. White squares denote the mean. 


\section{Bicycles}

Results are shown in Figure S9. Those trials where participants responded incorrectly $(1.5 \%)$, or where they took longer than $5 \mathrm{~s}$ to respond $(0.8 \%)$, were excluded from the analysis. The search advantage for facing dyads was seen independently for arrows. Front-to-front targets $(M=1.41 \mathrm{~s}, S D=0.20 \mathrm{~s})$ were found significantly faster than back-to-back targets $(M=1.61$ $\mathrm{s}, S D=0.33 \mathrm{~s})\left[t(39)=4.59, p<.001, d_{z}=0.72, \mathrm{Cl}_{95 \%}=0.11 \mathrm{~s}, 0.29 \mathrm{~s}\right]$. ANOVA with Arrangement (front-to-front, back-to-back) and Stimulus (arrows, cameras) as within-subjects factors revealed a significant Arrangement $\times$ Stimulus interaction $\left[F(1,39)=5.98, p=.019, \eta_{p}^{2}\right.$ $=.13]$. A significant correlation was seen between participants' search advantage for arrows and bicycles $\left[r_{p}=.415, p=.008\right]$.

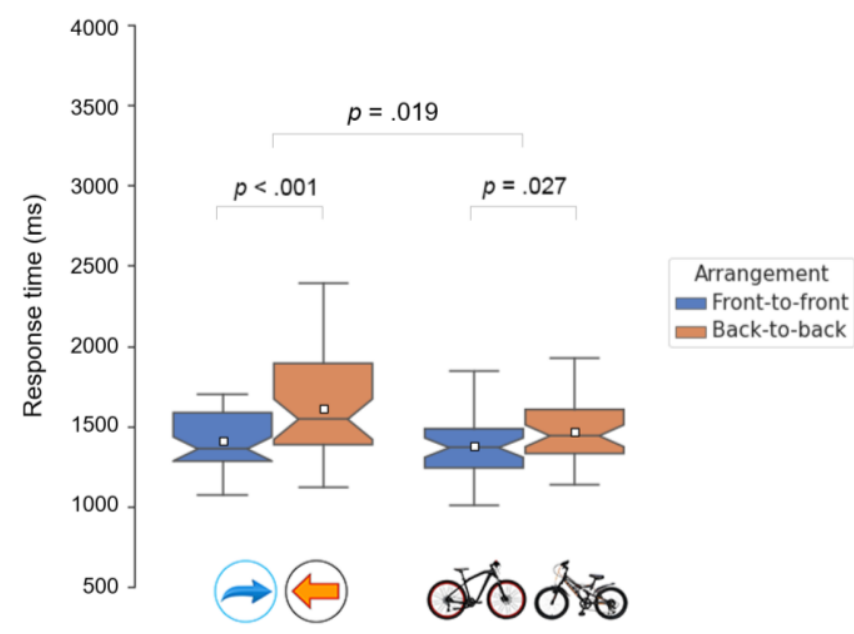

Figure S9. Results from the bicycles experiment. Boxes indicate inter-quartile range. Notches indicate confidence interval of the median. Whiskers indicate $1.5^{*}$ interquartile range. White squares denote the mean.

\section{Drills}

Results are shown in Figure S10. Those trials where participants responded incorrectly $(1.7 \%)$, or where they took longer than $5 \mathrm{~s}$ to respond $(1.0 \%)$, were excluded from the analysis. The search advantage for facing dyads was seen independently for arrows. Front-tofront targets $(M=1.47 \mathrm{~s}, S D=0.22 \mathrm{~s})$ were found significantly faster than back-to-back targets $(M=1.74 \mathrm{~s}, S D=0.31 \mathrm{~s})\left[t(39)=6.37, p<.001, d_{z}=1.01, \mathrm{Cl}_{95 \%}=0.19 \mathrm{~s}, 0.36 \mathrm{~s}\right]$. ANOVA with Arrangement (front-to-front, back-to-back) and Stimulus (arrows, cars) as withinsubjects factors revealed no Arrangement $\times$ Stimulus interaction $\left[F(1,39)=0.76, p=.390, n_{\mathrm{p}}^{2}\right.$ $=.02]$. A significant correlation was seen between participants' search advantage for arrows and drills $\left[r_{p}=.424, p=.006\right]$.

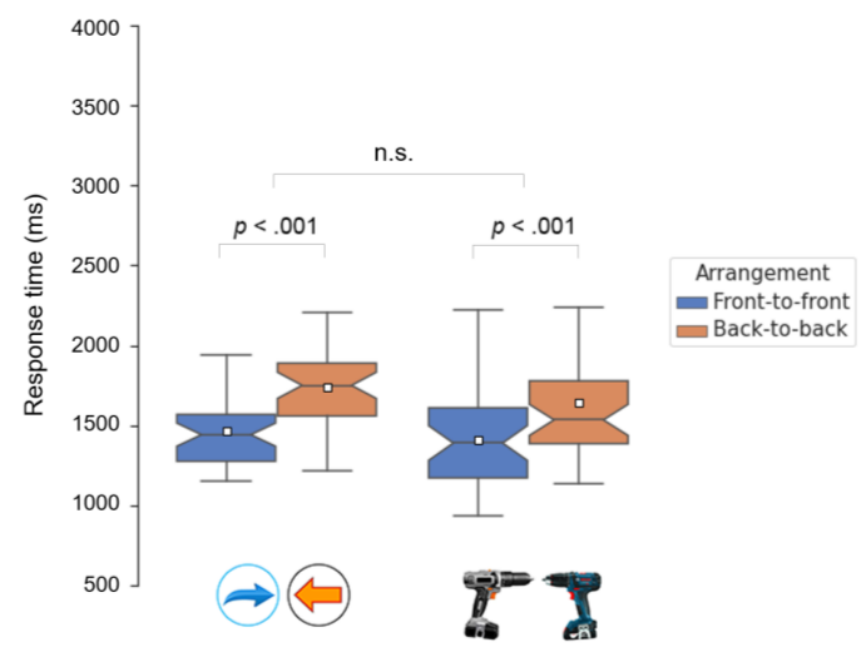

Figure S10. Results from the power drills experiment. Boxes indicate inter-quartile range. Notches indicate confidence interval of the median. Whiskers indicate $1.5 *$ interquartile range. White squares denote the mean. 


\section{Shoes}

Results are shown in Figure S11. Those trials where participants responded incorrectly $(1.8 \%)$, or where they took longer than $5 \mathrm{~s}$ to respond $(1.2 \%)$, were excluded from the analysis. The search advantage for facing dyads was seen independently for arrows. Front-tofront targets $(M=1.46 \mathrm{~s}, S D=0.34 \mathrm{~s})$ were found significantly faster than back-to-back targets $(M=1.60 \mathrm{~s}, S D=0.38 \mathrm{~s})\left[t(39)=3.47, p=.001, d_{z}=0.55, \mathrm{Cl}_{95 \%}=0.06 \mathrm{~s}, 0.21 \mathrm{~s}\right]$. ANOVA with Arrangement (front-to-front, back-to-back) and Stimulus (arrows, chairs) as within-subjects factors revealed no Arrangement $\times$ Stimulus interaction $[F(1,39)=3.01, p=$ $\left..091, \mathrm{np}^{2}=.07\right]$. No correlation was seen between participants' search advantage for arrows and shoes $\left[r_{p}=.109, p=.503\right]$.

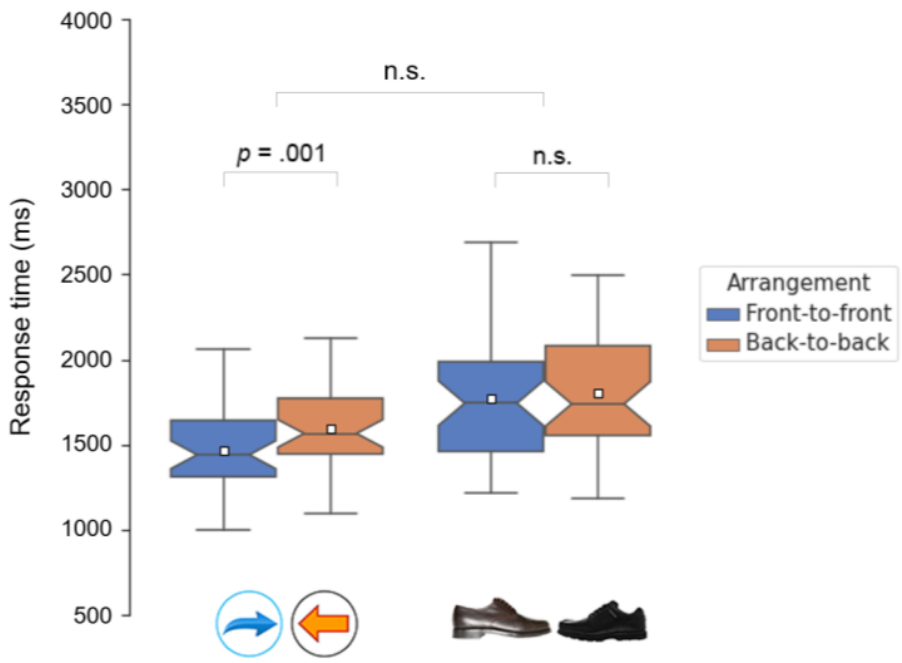

Figure S11. Results from the shoes experiment. Boxes indicate inter-quartile range. Notches indicate confidence interval of the median. Whiskers indicate $1.5^{*}$ interquartile range. White squares denote the mean. 